\section{Tuberculosis and impaired IL-23-dependent IFN- $\gamma$ immunity in humans homozygous for a common TYK2 missense variant}

\author{
Stéphanie Boisson-Dupuis ${ }^{1,2,3_{*}{ }^{\dagger}}$, Noe Ramirez-Alejo ${ }^{1 \dagger}$, Zhi Li $^{4,5 \ddagger}$, Etienne Patin ${ }^{6,7,8 \ddagger}$, Geetha Rao ${ }^{9 \ddagger}$, \\ Gaspard Kerner $^{2,3 \neq}$, Che Kang Lim ${ }^{10,11 \neq}$, Dimitry N. Krementsov ${ }^{12 \ddagger}$, Nicholas Hernandez ${ }^{1}$, Cindy S. Ma ${ }^{9,13}$, \\ Qian Zhang 1,14, Janet Markle ${ }^{1}$, Ruben Martinez-Barricarte', Kathryn Payne ${ }^{\text {, }}$, Robert Fisch 1, \\ Caroline Deswarte $^{2,3}$, Joshua Halpern ${ }^{1}$, Matthieu Bouaziz ${ }^{2,3}$, Jeanette Mulwa ${ }^{\text {, Durga Sivanesan }}{ }^{15,16}$, \\ Tomi Lazarov ${ }^{17}$, Rodrigo Naves ${ }^{18}$, Patricia Garcia ${ }^{19}$, Yuval Itan ${ }^{1,20,21}$, Bertrand Boisson ${ }^{1,2,3}$, Alix Checchi ${ }^{2,3}$, \\ Fabienne Jabot-Hanin ${ }^{2,3}$, Aurélie Cobat ${ }^{2,3}$, Andrea Guennoun ${ }^{14}$, Carolyn C. Jackson ${ }^{1,22}$, \\ Sevgi Pekcan ${ }^{23}$, Zafer Caliskaner ${ }^{24}$, Jaime Inostroza ${ }^{25}$, Beatriz Tavares Costa-Carvalho ${ }^{26}$, \\ Jose Antonio Tavares de Albuquerque ${ }^{27}$, Humberto Garcia-Ortiz ${ }^{28}$, Lorena Orozco ${ }^{28}$, \\ Tayfun Ozcelik ${ }^{29}$, Ahmed Abid ${ }^{30}$, Ismail Abderahmani Rhorfi ${ }^{30,31}$, Hicham Souhi ${ }^{30}$, \\ Hicham Naji Amrani ${ }^{30}$, Adil Zegmout ${ }^{30}$, Frédéric Geissmann ${ }^{17}$, Stephen W. Michnick ${ }^{15}$, \\ Ingrid Muller-Fleckenstein ${ }^{31}$, Bernhard Fleckenstein ${ }^{31}$, Anne Puel ${ }^{1,2,3}$, Michael J. Ciancanelli ${ }^{1}$, \\ Nico Marr ${ }^{14}$, Hassan Abolhassani ${ }^{10,32}$, María Elvira Balcells ${ }^{33}$, Antonio Condino-Neto ${ }^{27}$, \\ Alexis Strickler ${ }^{34}$, Katia Abarca ${ }^{35}$, Cory Teuscher ${ }^{36}$, Hans D. Ochs ${ }^{37}$, Ismail Reisli ${ }^{38}$, Esra H. Sayar ${ }^{38}$, \\ Jamila El-Baghdadi ${ }^{39}$, Jacinta Bustamante ${ }^{1,2,3,40 \S}$, Lennart Hammarström ${ }^{10,11,41 \S}$, Stuart G. Tangye ${ }^{9,13 \S}$, \\ Sandra Pellegrini ${ }^{4,5 \S}$, Lluis Quintana-Murci ${ }^{6,7,8 \S}$, Laurent Abel ${ }^{1,2,3 \|}$, Jean-Laurent Casanova ${ }^{1,2,3,42,43 *}{ }^{\prime \prime}$
}

The Authors, some rights reserved; exclusive licensee American Association for the Advancement of Science. No claim to original U.S.

Government Works

\begin{abstract}
Inherited IL-12R $\beta 1$ and TYK2 deficiencies impair both IL-12- and IL-23-dependent IFN- $\gamma$ immunity and are rare monogenic causes of tuberculosis, each found in less than $1 / 600,000$ individuals. We show that homozygosity for the common TYK2 P1104A allele, which is found in about 1/600 Europeans and between 1/1000 and 1/10,000 individuals in regions other than East Asia, is more frequent in a cohort of patients with tuberculosis from endemic areas than in ethnicity-adjusted controls $\left(P=8.37 \times 10^{-8}\right.$; odds ratio, $89.31 ; 95 \% \mathrm{Cl}, 14.7$ to 1725$)$. Moreover, the frequency of P1104A in Europeans has decreased, from about $9 \%$ to $4.2 \%$, over the past 4000 years, consistent with purging of this variant by endemic tuberculosis. Surprisingly, we also show that TYK2 P1104A impairs cellular responses to IL-23, but not to IFN- $\alpha$, IL-10, or even IL-12, which, like IL-23, induces IFN- $\gamma$ via activation of TYK2 and JAK2. Moreover, TYK2 P1104A is properly docked on cytokine receptors and can be phosphorylated by the proximal JAK, but lacks catalytic activity. Last, we show that the catalytic activity of TYK2 is essential for IL-23, but not IL-12, responses in cells expressing wild-type JAK2. In contrast, the catalytic activity of JAK2 is redundant for both IL-12 and IL-23 responses, because the catalytically inactive P1057A JAK2, which is also docked and phosphorylated, rescues signaling in cells expressing wild-type TYK2. In conclusion, homozygosity for the catalytically inactive P1104A missense variant of TYK2 selectively disrupts the induction of IFN- $\gamma$ by IL-23 and is a common monogenic etiology of tuberculosis.
\end{abstract}

\section{INTRODUCTION}

About a quarter of the world's population is infected with Mycobacterium tuberculosis, but this bacterium causes tuberculosis in less than $10 \%$ of infected individuals, generally within 2 years of infection (a situation referred to here as primary tuberculosis) (1-3). In the countries in which tuberculosis is highly endemic, primary tuberculosis is particularly common in children, who often develop life-threatening disease (4-6). Clinical and epidemiological studies have long suggested that tuberculosis in humans has a strong genetic basis (7-9). Autosomal recessive (AR) complete interleukin-12 receptor $\beta 1$ (IL-12R $\beta 1$ ) and tyrosine kinase 2 (TYK2) deficiencies are the only two inborn errors of immunity reported to date to underlie primary tuberculosis in otherwise healthy patients in two or more kindreds (10-17). Cells from patients with IL-12R $\beta 1$ deficiency do not respond to IL-12 or IL-23 $(12,18-24)$. These patients are susceptible to weakly virulent mycobacteria, such as the Bacille Calmette-Guérin (BCG) vaccine and environmental species [Mendelian susceptibility to mycobacterial disease (MSMD)], to the more virulent species M. tuberculosis, and more rarely to Candida albicans $(20,25)$. They are prone to MSMD and tuberculosis because they produce too little interferon- $\gamma$ (IFN- $\gamma$ ) $(7,12,26,27)$ and, in some cases, to chronic mucocutaneous candidiasis (CMC) because they produce too little IL-17A/F (28-32).

In patients with TYK2 deficiency, cellular responses to IL-12 and IL-23 are severely impaired, but not abolished (10, 33-35). These patients are, thus, also prone to MSMD and tuberculosis, although probably with a lower penetrance than for IL-12R $\beta 1$ deficiency, because they display residual responses to IL-12 and IL-23. They do not seem to be susceptible to $C$. albicans, which may merely reflect the lower penetrance of candidiasis and smaller number of patients, when compared with IL-12R $\beta 1$ deficiency. However, unlike patients with IL-12R $\beta 1$ deficiency, they are susceptible to viral diseases due to the impairment of their responses to $\operatorname{IFN}-\alpha / \beta(10,36)$. In vitro, their cells respond poorly to IL-10, but this defect, which is not observed in patients with IL-12R $\beta 1$ deficiency, is clinically silent $(10,37,38)$. Both IL-12R $\beta 1$ and TYK2 deficiencies are caused by rare or private alleles, accounting for each deficiency being found in 
no more than $1 / 600,000$ individuals worldwide. Here, we tested the hypothesis that two common and catalytically inactive missense TYK2 variants, P1104A and I684S (39), might underlie MSMD, tuberculosis, or both.

\section{RESULTS \\ Ten homozygotes for TYK2 P1104A suffered from mycobacterial diseases}

The common TYK2 variants P1104A (rs34536443) and I684S (rs12720356) are both catalytically impaired, as shown by in vitro kinase assays in reconstituted TYK2-deficient fibrosarcoma cells (U1A cells) (39). Other studies with selective small-molecule kinase inhibitors suggested that the catalytic activity of TYK2 was required for T cell responses to IL-12 and IL-23, but not IFN- $\alpha$ and IL-10 (40). Consistently, the P1104A variant has been reported to impair cellular responses to both IL-12 and IL-23 in human memory T cells, whereas discordant results were obtained for $\operatorname{IFN}-\alpha(39,41)$. The response to IL-10 was normal in human leukocytes (41). On the basis of the gnomAD database (42) (gnomAD: http://gnomad. broadinstitute.org), these two missense variants are rare $(<0.02 \%)$ in East Asian populations, but otherwise common $(>0.8 \%)$ in the other four main gnom $\mathrm{AD}$ populations, reaching their highest frequencies in Europeans (4.2\% for P1104A and 9\% for I684S) (fig. S1, $\mathrm{A}$ and B) $(43,44)$. On the basis of the 1000 Genomes Project database (45), these two variants are not in linkage disequilibrium. We investigated the possibility that these variants might confer a predisposition to MSMD, tuberculosis, or both. We screened our whole-exome sequencing (WES) data for 463 patients with MSMD and 291 children with tuberculosis, from different geographic locations and ancestries, and for 163 adults of North African ancestry with early-onset pulmonary tuberculosis (table S1). None of these patients carried pathogenic mutations in known MSMD- and tuberculosis-causing genes $(12,46)$. Our WES data for 2835 other patients, from various ethnic origins (fig. S1C) and with various genetically unexplained non-mycobacterial infections, were used as a control. Among the 3752 exomes available in total, we identified 366 I684S heterozygotes, 168 P1104A heterozygotes, 18 I684S homozygotes, and 6 I684S/P1104A compound heterozygotes, with no clustering of any of these genotypes within any of the patient cohorts (table S1). By contrast, we identified 11 unrelated P1104A homozygotes, which were confirmed by Sanger sequencing: 7 with tuberculosis ( 3 children under the age of 15 years and 4 adults under the age of 40 years), 3 with MSMD (all under 3 years of age), and 1 with CMC (aged 1 year) (Fig. 1, A to C; fig. S1D; and Supplementary Materials and Methods). We further Sanger sequenced TYK2 in parents and siblings of these 11 patients. We found that, in kindred $\mathrm{K}$ with the CMC patient, homozygosity for P1104A did not segregate with $\mathrm{CMC}$, because one sibling with $\mathrm{CMC}$ was heterozygous for $\mathrm{P} 1104 \mathrm{~A}$, implying that there is another genetic cause for CMC in this kindred (fig. S1D). We also found only one asymptomatic P1104A homozygote among the relatives of the other 10 patients (kindred G, I.1). In total, we identified 10 unrelated P1104A TYK2 homozygotes with MSMD (3 patients) or primary tuberculosis (7 patients).

\section{P1 104A homozygosity is strongly enriched in patients with tuberculosis}

Principal components analysis (PCA) based on the WES data (fig. S1C) (47) confirmed the diverse ancestries of the 10 patients. Eight were living in their countries of origin (Fig. 1C and fig. S1B). The Mexican patient was living in the United States, and the 10th patient, who was living in Brazil, had mixed European and African ancestry. We compared the proportions of individuals with P1104A in each cohort and estimated odds ratios (ORs) by logistic regression, with adjustment for the first three principal components of the PCA to account for ethnic heterogeneity (48). In addition to the 2835 exomes already used as controls, we used all 2504 available

\begin{abstract}
${ }^{1}$ St. Giles Laboratory of Human Genetics of Infectious Diseases, Rockefeller Branch, Rockefeller University, New York, NY, USA. ${ }^{2}$ Laboratory of Human Genetics of Infectious Diseases, Necker Branch, INSERM U1163, Paris, France. ${ }^{3}$ Paris Descartes University, Imagine Institute, Paris, France. ${ }^{4}$ Cytokine Signaling Unit, Pasteur Institute, Paris, France. ${ }^{5}$ INSERM U1221, Paris, France. ${ }^{6}$ Human Evolutionary Genetics Unit, Pasteur Institute, Paris, France. ${ }^{7}$ CNRS UMR2000, Paris, France. ${ }^{8}$ Center of Bioinformatics, Biostatistics and Integrative Biology, Pasteur Institute, Paris, France. ${ }^{9}$ Immunology Division, Garvan Institute of Medical Research, Darlinghurst, New South Wales, Australia. ${ }^{10}$ Division of Clinical Immunology, Department of Laboratory Medicine, Karolinska Institute, Karolinska University Hospital Huddinge, Stockholm, Sweden. ${ }^{11}$ Department of Clinical Translational Research, Singapore General Hospital, Singapore, Singapore. ${ }^{12}$ Department of Biomedical and Health Sciences, University of Vermont, Burlington, VT, USA. ${ }^{13}$ St. Vincent's Clinical School, University of New South Wales, Darlinghurst, New South Wales, Australia. ${ }^{14}$ Sidra Medicine, Doha, Qatar. ${ }^{15}$ Department of Biochemistry, University of Montreal, Montreal, Quebec, Canada. ${ }^{16}$ Department of Biochemistry, Microbiology, and Immunology, University of Ottawa, Ottawa, Ontario, Canada. ${ }^{17}$ Immunology Program, Sloan Kettering Institute, Memorial Sloan Kettering Cancer Center, New York, NY, USA. ${ }^{18}$ Institute of Biochemical Sciences, Faculty of Medicine, University of Chile, Santiago, Chile. ${ }^{19}$ Laboratory of Microbiology, Clinical Laboratory Department School of Medicine, Pontifical Catholic University of Chile, Santiago, Chile. ${ }^{20}$ The Charles Bronfman Institute for Personalized Medicine, Icahn School of Medicine at Mount Sinai, New York, NY, USA. ${ }^{21}$ Department of Genetics and Genomic Sciences, Icahn School of Medicine at Mount Sinai, New York, NY, USA. ${ }^{22}$ Department of Pediatrics, Memorial Sloan Kettering Cancer Center, New York, NY, USA. ${ }^{23}$ Department of Pediatric Pulmonology, Necmettin Erbakan University, Meram Medical Faculty, Konya, Turkey. ${ }^{24}$ Meram Faculty of Medicine, Department of Internal Medicine, Division of Allergy and Immunology, Necmettin Erbakan University, Konya, Turkey. ${ }^{25}$ Jeffrey Modell Center for Diagnosis and Research in Primary Immunodeficiencies, Faculty of Medicine University of La Frontera, Temuco, Chile. ${ }^{26}$ Department of Pediatrics, Federal University of São Paulo Medical School, São Paulo, Brazil. ${ }^{27}$ Department of Immunology, Institute of Biomedical Sciences, and Institute of Tropical Medicine, University of São Paulo, São Paulo, Brazil. ${ }^{28}$ National Institute of Genomic Medicine, Mexico City, Mexico. ${ }^{29}$ Department of Molecular Biology and Genetics, Bilkent University, Ankara, Turkey. ${ }^{30}$ Department of Pneumology, Military Hospital Mohammed V, Rabat, Morocco. ${ }^{31}$ Institute of Clinical and Molecular Virology, University of Erlangen-Nuremberg, Erlangen, Germany. ${ }^{32}$ Research Center for Immunodeficiencies, Pediatrics Center of Excellence, Children's Medical Center, Tehran University of Medical Sciences, Tehran, Iran. ${ }^{33}$ Department of Infectious Diseases, Medical School, Pontifical Catholic University of Chile, Santiago, Chile. ${ }^{34}$ Department of Pediatrics, San Sebastián University, Santiago, Chile. ${ }^{35}$ Department of Infectious Diseases and Pediatric Immunology, School of Medicine, Pontifical Catholic University of Chile, Santiago, Chile. ${ }^{36}$ Department of Medicine, Immunobiology Program, University of Vermont, Burlington, VT, USA. ${ }^{37}$ Seattle Children's Research Institute and Department of Pediatrics, University of Washington, Seattle, WA, USA. ${ }^{38}$ Department of Pediatric Immunology and Allergy, Necmettin Erbakan University, Meram Medical Faculty, Konya, Turkey. ${ }^{39}$ Genetics Unit, Military Hospital Mohamed V, Hay Riad, Rabat, Morocco. ${ }^{40}$ Center for the Study of Primary Immunodeficiencies, AP-HP, Necker Hospital for Sick Children, Paris, France. ${ }^{41}$ Beijing Genomics Institute BGI-Shenzhen, Shenzhen, China. ${ }^{42}$ Pediatric Hematology-Immunology Unit, Necker Hospital for Sick Children, AP-HP, Paris, France. ${ }^{43}$ Howard Hughes Medical Institute, New York, NY, USA.
\end{abstract}

*Corresponding author. Email: stbo603@rockefeller.edu (S.B.-D.); jean-laurent.casanova@rockefeller.edu (J.-L.C.)

tThese authors contributed equally to this work.

¥These authors contributed equally to this work.

$\S$ These authors contributed equally to this work.

||These authors contributed equally to this work. 
A

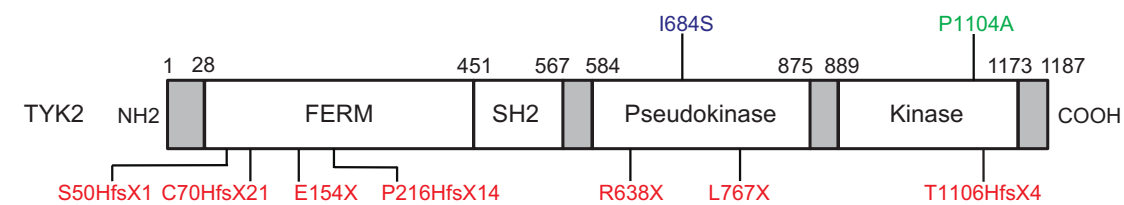

B

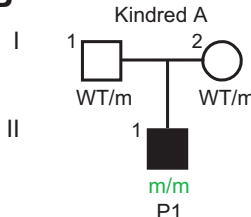

$$
\text { Kindred } \mathrm{F}
$$

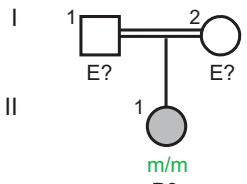

P6
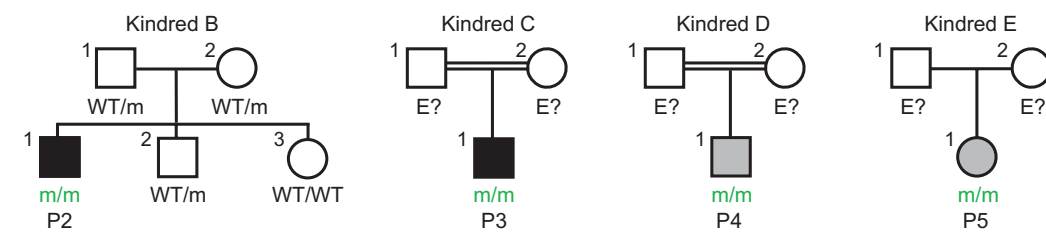

Kindred $\mathrm{H}$
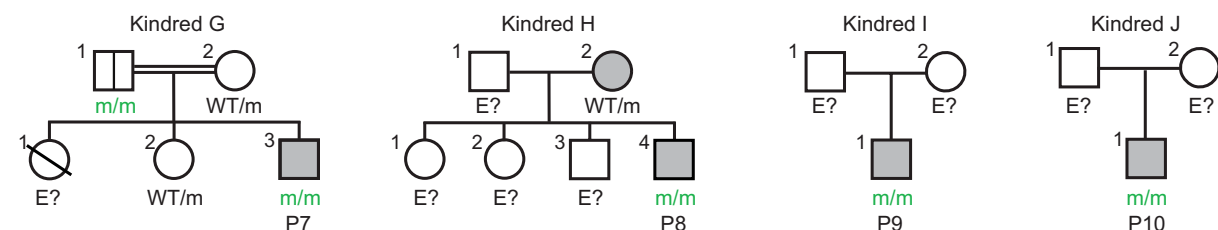

\begin{tabular}{|c|c|c|c|c|c|c|c|c|c|}
\hline C & Patients & Disease & $\begin{array}{c}\text { Country } \\
\text { of residence }\end{array}$ & Origin by PCA & $\begin{array}{c}\% \\
\text { Homoz@ }\end{array}$ & $\begin{array}{c}\text { MAF } \\
\text { gnomAD\# }\end{array}$ & $\begin{array}{c}\text { TB incidence }{ }^{*} \\
(/ 100,000)\end{array}$ & $\begin{array}{c}\text { BCG } \\
\text { vaccination }\end{array}$ & $\begin{array}{l}\text { Age of onset of } \\
\text { symptoms (years) }\end{array}$ \\
\hline \multirow{3}{*}{ MSMD } & $\mathrm{P} 1$ & BCG osteomyelitis & Sweden & European & 0.41 & 0.042 & 9.2 & Yes & 1 \\
\hline & P2 & MAC osteomyelitis & USA & American/Mexican & 1.58 & 0.012 & 3.2 & No & 1 \\
\hline & P3 & BCG disseminated & Iran & Middle Eastern & 3.27 & 0.031 & 15 & Yes & 2 \\
\hline \multirow{7}{*}{ TB } & P4 & Pulmonary & Brazil & Mixed European/African & 2.85 & 0.018 & 41 & Yes & 6 \\
\hline & P5 & Pulmonary & Algeria & North African & 1.48 & 0.018 & 75 & Yes & 40 \\
\hline & P6 & Pulmonary & Morocco & North African & 4.16 & 0.018 & 107 & Yes & 27 \\
\hline & P7 & Miliary & Turkey & Turkish & 5.53 & 0.021 & 18 & Yes & 15 \\
\hline & P8 & Pulmonary & Chile & American/Chilean & 0.6 & 0.012 & 16 & Yes & 13 \\
\hline & P9 & Pulmonary & Morocco & North African & 0.82 & 0.018 & 107 & Yes & 35 \\
\hline & $\mathrm{P} 10$ & Pulmonary & Chile & American/Chilean & 0.27 & 0.012 & 16 & Yes & 33 \\
\hline
\end{tabular}

@: Percentage of homozygosity

\#: Allele frequency in the country of origin in the gnomAD database

${ }^{*}$ TB incidence in the country of residence from WHO 2015

\begin{tabular}{|c|c|c|c|c|c|c|c|c|c|c|}
\hline & Controls & \multicolumn{3}{|c|}{ Tuberculosis } & \multicolumn{3}{|c|}{ MSMD } & \multicolumn{3}{|c|}{ TB + MSMD } \\
\hline & $(n=5339)$ & \multicolumn{3}{|c|}{$(n=454)$} & \multicolumn{3}{|c|}{$(n=463)$} & \multicolumn{3}{|c|}{$(n=917)$} \\
\hline Variant & $\begin{array}{l}\text { Homoz. } \\
\text { carriers }\end{array}$ & $\begin{array}{l}\text { Homoz. } \\
\text { carriers }\end{array}$ & $\begin{array}{c}\text { OR } \\
(95 \% \mathrm{Cl})\end{array}$ & $P$ value & $\begin{array}{l}\text { Homoz. } \\
\text { carriers }\end{array}$ & $\begin{array}{c}\text { OR } \\
(95 \% \mathrm{Cl})\end{array}$ & $P$ value & $\begin{array}{l}\text { Homoz. } \\
\text { carriers }\end{array}$ & $\begin{array}{c}\text { OR } \\
(95 \% \mathrm{Cl})\end{array}$ & $P$ value \\
\hline P1104A & 1 & 7 & $\begin{array}{c}89.31 \\
(14.7-1725)\end{array}$ & $8.37 \times 10^{-8}$ & 3 & $\begin{array}{c}23.53 \\
(2.9-483)\end{array}$ & $3.27 \times 10^{-3}$ & 10 & $\begin{array}{c}53.72 \\
(10.1-993)\end{array}$ & $4.87 \times 10^{-8}$ \\
\hline $1684 \mathrm{~S}$ & 22 & 1 & $\begin{array}{c}0.46 \\
(0.03-2.2)\end{array}$ & 0.38 & 2 & $\begin{array}{c}0.76 \\
(0.12-2.6)\end{array}$ & 0.71 & 3 & $\begin{array}{c}0.61 \\
(0.15-1.8)\end{array}$ & 0.4 \\
\hline
\end{tabular}

E
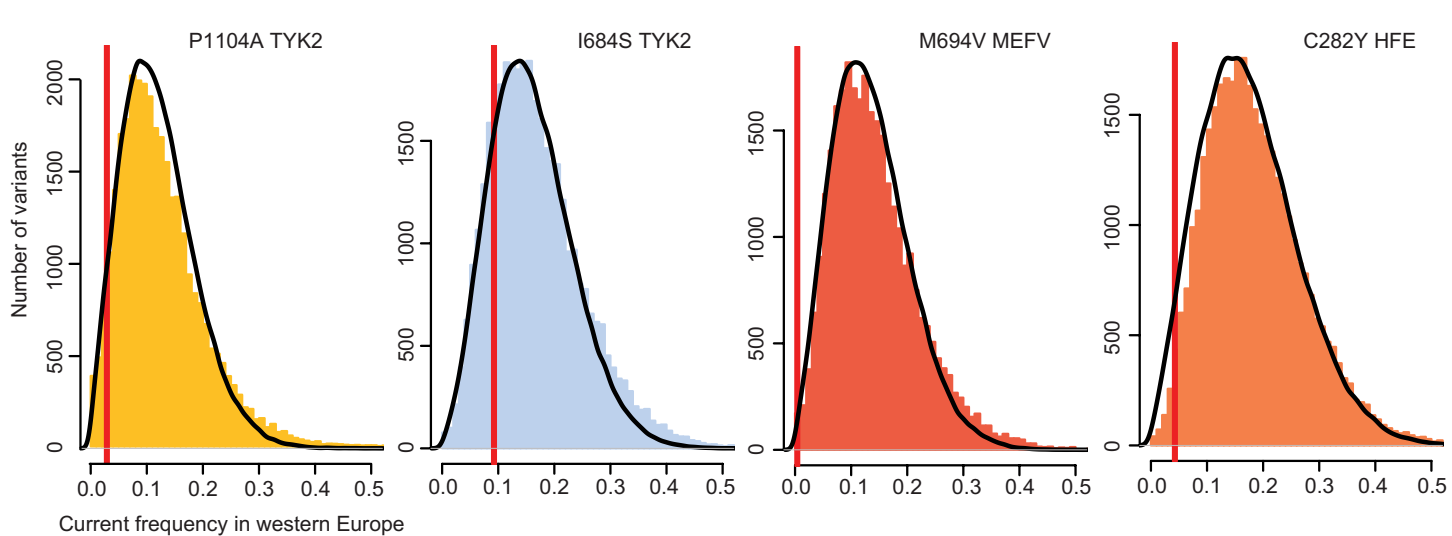

Current frequency in western Europe $\begin{array}{llll}0.1 & 0.2 & 0.3 & 0.4\end{array}$
Fig. 1. Familial segregation and clinical information for patients homozygous for TYK2 P1104A.

(A) Schematic diagram of the TYK2 protein with its various domains (FERM, SH2, pseudokinase, and tyrosine kinase). The positions of the previously reported $T Y K 2 \mathrm{mu}-$ tations resulting in premature STOP codons are indicated in red. The positions of the $1684 \mathrm{~S}$ and P1104A polymorphisms are indicated in blue and green, respectively. (B) Pedigrees of the 10 TYK2-deficient families. Each generation is designated by a Roman numeral (I-II), and each individual by an Arabic numeral. The double lines connecting the parents indicate consanguinity based on interview and/ or a homozygosity rate of $>4 \%$ estimated from the exome data. Solid shapes indicate disease status. Individuals whose genetic status could not be determined are indicated by " $E$ ?", and " $\mathrm{m}$ " indicates a TYK2 P1104A allele. (C) Summary table of clinical details and origin of the patients associated with the MAF in the country of origin. The incidence of tuberculosis (TB) in the country of residence is also mentioned. MAC indicates Mycobacterium avium complex. (D) Summary of WES, indicating the numbers of individuals with tuberculosis or MSMD and of controls carrying the $1684 \mathrm{~S}$ or P1 $104 \mathrm{~A}$ variant of TYK2 in the homozygous state, and the associated $P$ value and OR. (E) Distributions of the current allele frequencies of variants that segregated 4000 years ago at frequencies similar to those of the P1104A and 1684S TYK2, M694V MEFV, and C282Y HFE variants. The red vertical lines indicate the current frequency of the four variants of interest. Colored bars indicate the distribution of current allele frequency, in the 1000 Genomes Project, for variants with frequencies in ancient European human DNA similar to those of the four candidate variants (52). Black lines indicate the distribution of simulated frequencies, in the present generation, for alleles with a past frequency similar to that of the four candidate variants, with propagation over 160 generations (corresponding to a pe-

riod of $\sim 4000$ years) under the Wright-Fisher neutral model. For instance, for the P1104A allele, which had a frequency of $\sim 9 \%$ in ancient Europeans, colored bars indicate the observed distribution of current frequencies for the 31,276 variants with a frequency of 8 to $10 \% 4000$ years ago. The black lines indicate the distribution of frequencies for 100,000 simulated alleles obtained after 160 generations under the Wright-Fisher neutral model. 
individuals from the 1000 Genomes Project (45), giving a total of 5339 controls for whom we have complete WES data (Fig. 1D). P1104A homozygosity was more enriched among patients with MSMD than among controls $\left[P=3.27 \times 10^{-3}\right.$; OR, 23.53; $95 \%$ confidence interval (CI), 2.9 to 483], and an even higher level of enrichment was observed among patients with tuberculosis $(P=$ $8.37 \times 10^{-8}$; OR, $89.31 ; 95 \% \mathrm{CI}, 14.7$ to 1725$)$. The level of enrichment in homozygosity for this variant was intermediate but more significant when both groups were analyzed together (OR, 53.72; $95 \% \mathrm{CI}, 10.1$ to $993 ; P=4.87 \times 10^{-8}$ ). By contrast, no enrichment in homozygosity for this variant was observed among the patients with other infections studied in the laboratory (table S1) $(49,50)$. Aside from the $10 \mathrm{MSMD}$ and tuberculosis patients, we identified only one other P1104A homozygote by WES: a CMC patient whose P1104A homozygosity was not CMC-causing, living in the United States, where infants are not inoculated with BCG and M. tuberculosis is not endemic (fig. S1D). No homozygotes were observed among the 2504 individuals of the 1000 Genomes Project. No significant enrichment in P1104A heterozygosity was observed in any of the cohorts studied, including patients with $\operatorname{MSMD}(P=$ $0.57)$ or tuberculosis $(P=0.49)$, demonstrating the recessive nature of P1104A inheritance for both mycobacterial conditions. Moreover, no significant enrichment in I684S heterozygotes or homozygotes or in P1104A/I684S compound heterozygotes was observed in any of the cohorts studied (table S1). Last, the TYK2 $\mathrm{P} 1104 \mathrm{~A}$ allele yielded the highest OR at genome-wide level in an independent enrichment analysis performed under the assumption of a recessive mode of inheritance and considering all common missense or potential loss-of-function (LOF) alleles in our entire cohort of 3752 patients (fig. S1E). These results strongly suggest that homozygosity for P1104A is a genetic etiology of primary tuberculosis and MSMD.

\section{TYK2 P1 104A allele frequency has decreased in Europe over the past $\mathbf{4 0 0 0}$ years}

The higher risk of life-threatening tuberculosis in P1104A homozygotes suggests that this variant has been subject to negative selection in areas in which this disease has long been endemic, such as Europe (51). We analyzed changes in the frequencies of the P1104A and I684S TYK2 variants in the European population, from ancient to modern times (52). Only three nonsynonymous TYK2 variants-P1104A, I684S, and V362F-were found in an available sample of central European individuals who lived during the late Neolithic age $\sim 4000$ years ago (52). Over this period, the frequency of TYK2 P1104A has significantly decreased in Europeans, from about $9 \%$ to $4.2 \%$ (Fig. $1 \mathrm{E}$ ). Of the 31,276 variants with frequencies in the 8 to $10 \%$ range 4000 years ago, $\mathrm{P} 1104 \mathrm{~A}$ is among the $5 \%$ displaying the largest decrease in frequency (empirical $P=$ 0.048; Fig. 1E). Furthermore, the neutral model of evolution was significantly rejected for P1104A in Wright-Fisher simulations (simulation $P=0.050$; Fig. $1 \mathrm{E}$ and Supplementary Materials and Methods), suggesting an absence of bias in the empirical analyses. As a negative control, the frequency of V362F remained stable (from $25 \%$ to $26.2 \%$ ) and that of I684S did not decrease significantly over this period (empirical $P=0.181$ ). The frequency of I684S was about $14 \% 4000$ years ago and is now $9 \%$, placing this variant among the $80 \%$ of the 36,469 polymorphisms considered with a frequency that was in the 13 to $15 \%$ range 4000 years ago and has remained relatively stable.

\section{TYK2 P1 104A allele was possibly purged in Europe by tuberculosis}

We subsequently analyzed, as positive controls, two relatively common mutations known to cause life-threatening AR disorders and present in ancient Europeans: the MEFV M694V variant underlying Mediterranean fever (MF) (53) and the HFE C282Y underlying hemochromatosis (which also decreases male fertility) (54). Both these variants decreased significantly in frequency over the same period, from about $11 \%$ to $0.4 \%$ for $M E F V \mathrm{M} 694 \mathrm{~V}$ and from $16 \%$ to $5.7 \%$ for $H F E$ C282Y (empirical $P=0.016$ for both variants; Fig. 1E). Therefore, our preliminary assessments suggest that TYK2 P1104A, MEFV M694V, and HFE C282Y have been subject to negative selection in Europeans, whereas TYK2 I684S has not. The stronger selection operating on $M E F V \mathrm{M} 694 \mathrm{~V}$, and to a lesser extent HFE C282Y, than on TYK2 P1104A is consistent with the inevitability of $\mathrm{MF}$ and hemochromatosis in patients with these mutations, whereas tuberculosis development also requires exposure to $M$. tuberculosis. These results suggest that, unlike I684S, P1104A has been undergoing a purge in Europe since the Neolithic period due to the continued endemic nature of life-threatening tuberculosis (51). No other intramacrophagic infection, whose control depends on IFN- $\gamma$, has been endemic for so long in Europe $(55,56)$. The purging of deleterious mutations is expected to be much less effective in the absence of continued exposure $(57,58)$, which has been the case for other infections that killed a sizeable proportion of Europeans, albeit for no more than several decades or a few centuries, such as plague (59). The observed decline in P1104A allele frequency is consistent with the purging of a recessive trait that kills in childhood or when the individual is of reproductive age. This decrease would be much steeper for a dominant trait with a similar fitness effect. These results suggest that homozygosity for P1104A, which is still present in about $1 / 600$ Europeans and between $1 / 10,000$ and $1 / 1000$ individuals in other regions of the world, with the exception of East Asia, where the allele is almost absent, has been a major human genetic determinant of primary tuberculosis during the course of human history.

\section{TYK2 P1104A impairs IL-23 but not IFN- $\alpha$, IL-12, and IL-10 signaling}

We performed a functional characterization of the I684S and P1104A TYK2 alleles, focusing on the four known human TYK2dependent signaling pathways (10). In reconstituted U1A cells stimulated with IFN- $\alpha$ in vitro, both mutant proteins were previously shown to be catalytically inactive, i.e., unable to autophosphorylate or phosphorylate a substrate such as signal transducer and activator of transcription 3 (STAT3) (39). However, both could be phosphorylated by Janus kinase 1 (JAK1), unlike the prototypical kinase-dead adenosine $5^{\prime}$ triphosphate (ATP)-binding mutant K930R (39). Epstein-Barr virus (EBV)-transformed B (EBV-B) cells and herpesvirus saimiri (HVS)-transformed T (HVS-T) cells derived from a TYK2-deficient patient without TYK2 protein expression (10) were stably transduced with a retrovirus generated with an empty vector or a vector containing the wild-type (WT), P1104A, I684S, or K930R TYK2 complementary DNA (cDNA) (60). Transduction with the WT or any mutant TYK2 restored both TYK2 expression, as shown by Western blotting, and the corresponding TYK2 scaffolding-dependent surface expression of IFN- $\alpha$ R1, IL-10R2, and IL-12R $\beta 1$, as shown by flow cytometry (Fig. 2, A and B, and fig. S2, A and B). In P1104A-expressing cells, the IFN- $\alpha$ - and IL-12dependent signaling pathways were normal, as shown by the levels 
A

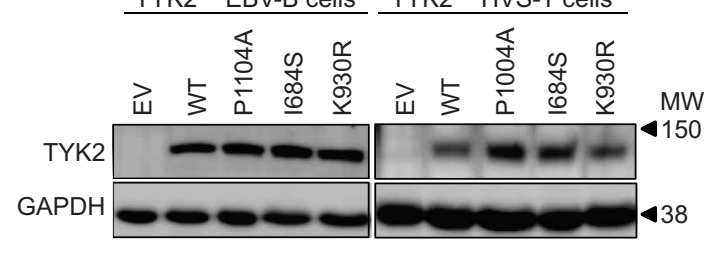

C
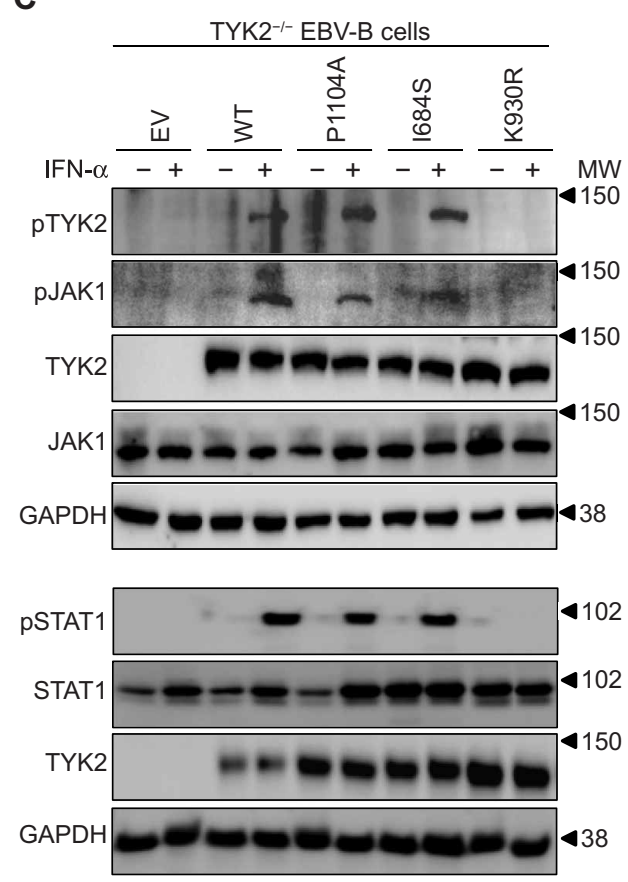

E

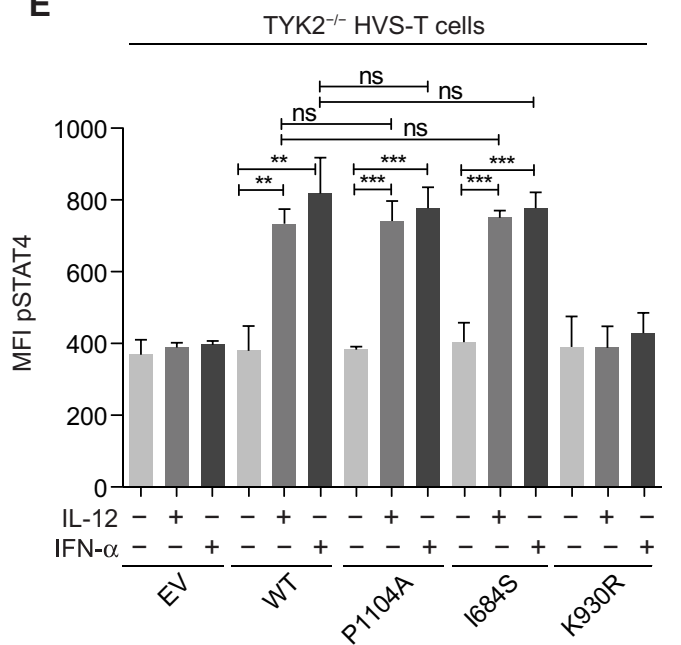

B

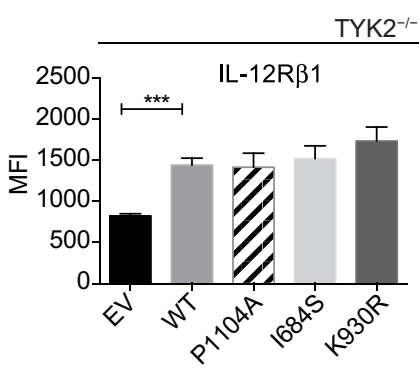

D
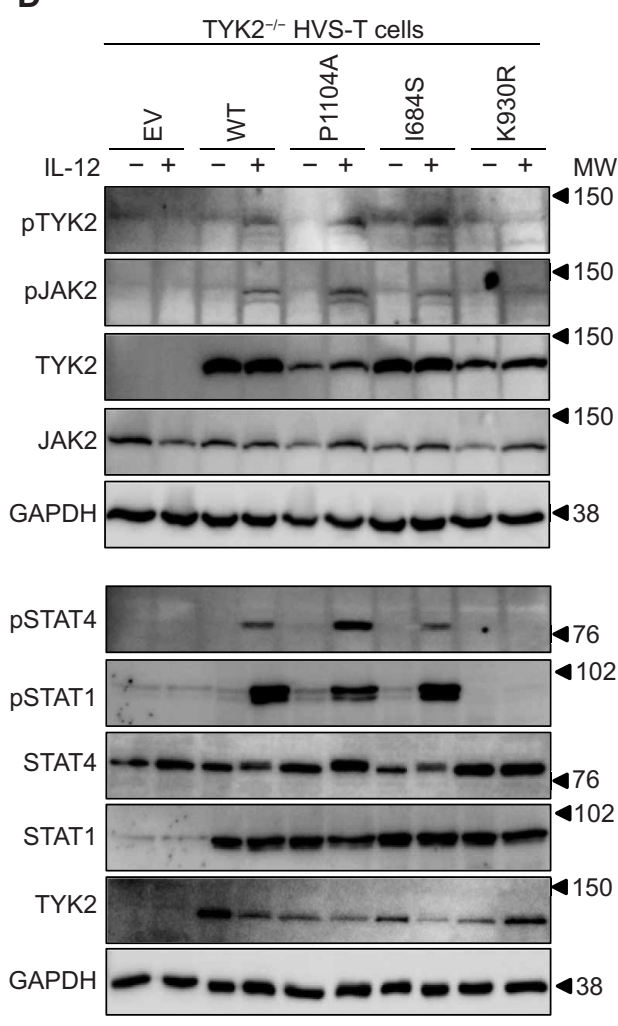

G

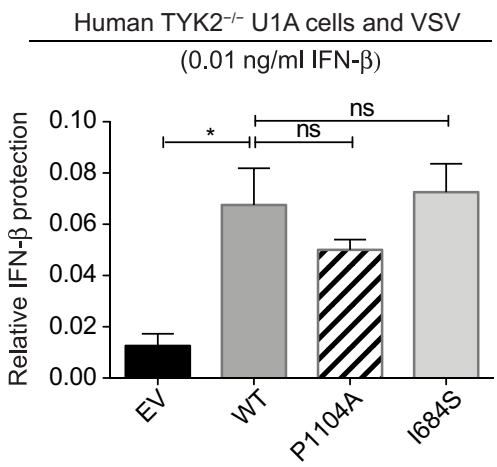

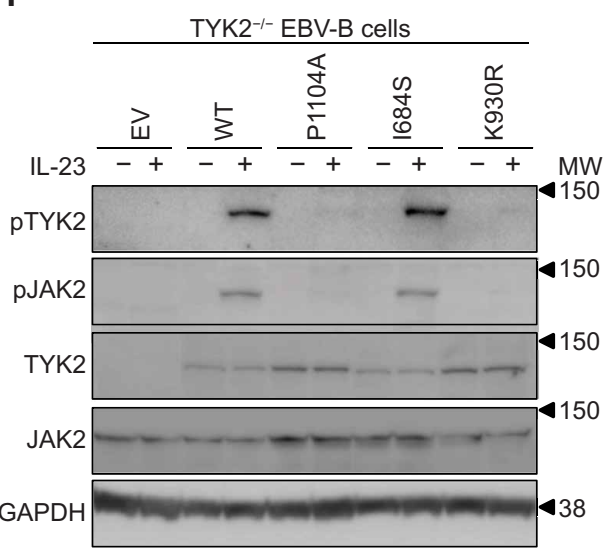

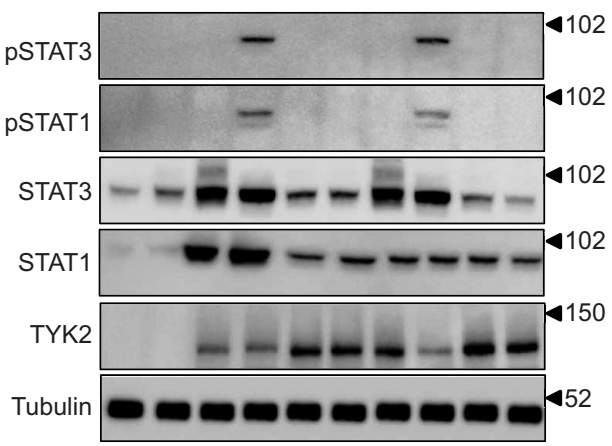

Mouse TYK2 $2^{-1-}$ MEF cells and VSV

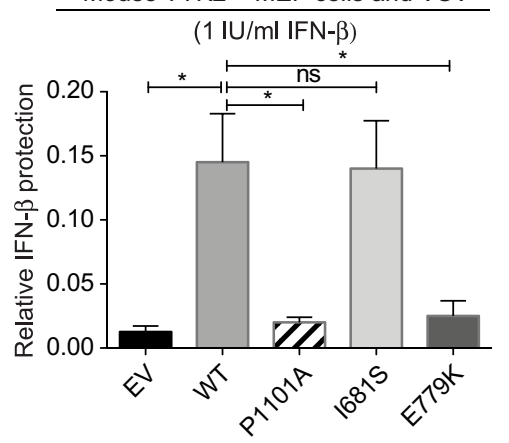

Fig. 2. Cellular responses to IFN- $\alpha$, IL-12 and IL-23 in transduced EBV-B and HVS-T cells. TYK2-deficient EBV-B and HVS-T cells were transduced with a retrovirus generated with an empty vector (EV), or vectors encoding WT TYK2, or the P1104A, 1684S, or K930R TYK2 alleles. (A) Levels of TYK2 in transduced EBV-B (left) and HVS-T (right) cells, as determined by Western blotting. (B) Levels of IL-12R 1 and IFN- $\alpha$ R1 in transduced EBV-B (left) and HVS-T (right) cells, as determined by flow cytometry. ${ }^{* * *} P<$ 0.001, two-tailed Student's $t$ test. Error bars indicate SEM. (C, D, and F) Phosphorylation of JAKs and STATs in unstimulated (-) transduced EBV-B or HVS-T cells or in these cells after stimulation (+) with IFN- $\alpha$ (C) (pTYK2, pJAK1, and pSTAT1), IL-12 (D) (pTYK2, pJAK2, pSTAT1, and pSTAT4), and IL-23 (F) (pTYK2, pJAK2, pSTAT3, and pSTAT1), as assessed by Western blotting with specific antibodies recognizing phospho-TYK2, phospho-JAK1, phospho-JAK2, phospho-STAT1, phospho-STAT4, and phospho-STAT3. MW, molecular weight. (E) Phosphorylation of STAT4 in response to IFN- $\alpha$ and IL-12, as determined by flow cytometry in HVS-transduced T cells and expression as mean fluorescence intensity (MFI). ${ }^{* *} P<0.01,{ }^{* * *} P<0.001$, two-tailed Student's $t$ test. ns, not significant. (G) IFN- $\beta$ response of U1A (left) and MEF (right) cells, both lacking TYK2, after transduction with the indicated human and mouse TYK2 alleles, respectively, or with empty vector control, as measured in an IFN- $\beta$-induced antiviral activity assay (see Materials and Methods). A unique dose is shown: an IFN- $\beta$ dose of $0.01 \mathrm{ng} / \mathrm{ml}$ for human cells and $1 \mathrm{IU} / \mathrm{ml}$ for mouse cells. 
of induced phosphorylation of the key components [TYK2, JAK1, STAT1, and STAT3 for IFN- $\alpha$; TYK2, JAK2, STAT1, and STAT4 for IL-12] (Fig. 2, C to E, and fig. S2, C, D, and H). All Western blots were quantified, as shown in the supplementary figures. No phosphorylation of TYK2 or JAK1 was detected after stimulation with IL-10, despite only very slight decreases in the phosphorylation of STAT3 and STAT1, as shown by Western blotting and flow cytometry (fig. S2, E to H). In response to IL-23, the phosphorylation of TYK2, JAK2, and STAT3 was as severely impaired as observed in TYK2-deficient and K930R-transduced recipient cells (Fig. 2F and fig. S2, H and I). Stimulation with higher concentrations of IL-23 did not reverse this phenotype, but a residual response was observed in P1104A cells after longer periods of stimulation (fig. S2J). I684S cells responded normally to the four cytokines, whereas K930R cells did not respond at all. Because Pro ${ }^{1104}$ and Ile ${ }^{684}$ are located in two different domains of TYK2, their substitutions may differently affect cytokine-induced JAK activation. Our findings indicate that the expression of TYK2 I684S in TYK2deficient EBV-B and HVS-T cells rescues JAK-STAT activation in response to IFN- $\alpha$, IL-10, IL-12, and IL-23, whereas TYK2 P1104A expression selectively fails to rescue responses to IL-23.

\section{Human TYK2 P1104A, unlike mouse P1101A, rescues antiviral activity}

The impact of TYK2 variants on cellular responses to IL-12 and IL-23 is irrelevant in nonhematopoietic cells, because the receptors for these cytokines are expressed only on leukocytes. Yet, TYK2 variants may affect IFN- $\alpha / \beta$ and IL-10 responses in multiple cell types. To study the IFN- $\alpha / \beta$ response pathway, we measured the antiviral response to IFN- $\beta$ of U1A cells (61-63) stably transduced with a retroviral particle generated with an empty vector or a vector encoding the WT, P1104A, or I684S TYK2 cDNA. Cells were treated with increasing concentrations of IFN- $\beta$ and were then challenged with vesicular stomatitis virus (VSV), which is cytopathic. U1A cells transduced with an empty vector displayed almost no response to IFN- $\beta$, with high proportions of dead cells, whereas cells transduced with WT, P1104A, or I684S TYK2 responded robustly, with diminished proportions of dead cells (Fig. 2G, left, and fig. S2K, left). Both the I684S and P1104A mutant proteins are, therefore, functional for antiviral immunity mediated by IFN- $\beta$ in human fibrosarcoma cells, consistent with the results shown above for lymphocytes. We then expressed the orthologous mouse missense alleles (P1101 A and I681S) and a known mouse LOF missense allele (E779K, which impairs TYK2 expression and abolishes its function) in TYK2-deficient mouse embryonic fibroblasts (MEFs) (64). Protection against VSV infection was measured by assessing the response to increasing concentrations of IFN- $\beta$. P1101A and E779K did not protect, unlike WT and I681S TYK2 (Fig. 2G, right, and fig. S2K, right). Consistently, the P1101A variant did not restore the IFN- $\beta$-dependent inhibition of IFN- $\gamma$-induced major histocompatibility complex class II upregulation in mouse peritoneal macrophages (41). These overexpression data show that mouse TYK2 P1101A does not rescue IFN- $\alpha / \beta$ signaling in mouse fibroblasts, consistent with a previous study on lymphocytes (41), whereas human P1104A can rescue IFN- $\alpha / \beta$ signaling in human cells. The mouse P1101A variant has also been reported to impair cellular responses to IL-12 and IL-23 in lymphocytes (41). Thus, both the two human missense proteins (P1104A versus I684S, for IL-23) and the two orthologs (P1104A versus P1101A, for IFN- $\alpha / \beta$ and IL-12) have qualitatively different impacts on some TYK2-dependent pathways, at least when overexpressed. The other two orthologs (I684S versus I681S) behaved in a similar manner. Overall, the human P1104A allele did not disrupt responses to IFN- $\alpha / \beta$ in either lymphocytes or fibroblasts.

\section{IL-23 signaling is impaired in patients' cells homozygous for TYK2 P1104A}

The study of overexpressed mutant allele cDNAs captures different information than the study of cells carrying a biallelic genotype in the context of the patients' entire genome. Hence, we analyzed EBV-B and HVS-T cells from controls and patients homozygous for P1104A or I684S, compound heterozygous for P1104A and I684S, or with complete TYK2 deficiency, in the same experimental conditions. TYK2 levels were similar in cells with any of the three mutant genotypes other than complete TYK2 deficiency (Fig. 3A and fig. S3A). Cell surface expression of IFN- $\alpha$ R1 and IL-10R2 in EBV-B cells and of IL-12R $\beta 1$ in EBV-B and HVS-T cells was also normal, attesting to the intact scaffolding function of constitutively expressed P1104A and I684S (Fig. 3B and fig. S3B) (10). In P1104A homozygous cells, the response to IFN- $\alpha$ was modestly reduced in terms of JAK1, TYK2, STAT3, and STAT1 phosphorylation (Fig. 3C and fig. S3, C to F), whereas the response to IL-12 was normal, as shown by levels of JAK2, TYK2, and STAT4 phosphorylation (Fig. 3D and fig. S4, A to D). In the same experimental conditions, TYK2-deficient cells had severe phenotypes, in terms of phosphorylation of JAK1, TYK2, STAT1, STAT3 in response to IFN- $\alpha$, and JAK2, TYK2, and STAT4 in response to IL-12. In contrast, cells homozygous for I684S or compound heterozygous for I684S and P1104A had no detectable phenotype. As in TYK2-deficient cells, the phosphorylation of JAK1 and TYK2 in response to IL-10 was impaired in P1104A homozygous cells, as tested by Western blotting, whereas that of STAT3 was barely affected, as tested by flow cytometry (fig. S4, E to H). The phosphorylation of JAK2, TYK2, and STAT3 in response to IL-23, as assessed by Western blotting, was normal in I684S homozygous and I684S/P1104A compound heterozygous EBV-B cells, but equally and severely impaired in P1104A and TYK2-deficient EBV-B cells, despite the normal levels of IL-23R in these cells, as assessed by flow cytometry (Fig. 4A and fig. S5, A and B). Higher concentrations of IL-23 and longer periods of stimulation with this cytokine did not reverse this phenotype (fig. S5, C and D). Moreover, STAT3 phosphorylation was also impaired in P1104A HVS-T cells stimulated with IL-23, as assessed by flow cytometry (Fig. 4B). Thus, consistent with the results of previous overexpression studies, the constitutive expression of P1104A did not impair JAK-STAT responses to IL-12 and had only a modest effect on responses to IFN $-\alpha / \beta$ and IL-10, whereas it disrupted JAK-STAT responses to IL-23 as severely as complete TYK2 deficiency, in both EBV-B and HVS-T cells.

\section{The induction of target genes by IL-23 is impaired in patients' EBV-B cells}

We then assessed the more distal induction of target genes in control and patient EBV-B cells after stimulation with IL-10, IFN- $\alpha$, and IL-23. The induction of SOCS3 mRNA after stimulation with IL-10 was not significantly weaker in P1104A cells than in control cells, as shown by quantitative reverse transcription polymerase chain reaction (RT-qPCR) (fig. S6A). We also performed RNA-sequencing (RNA-seq) on EBV-B cells stimulated with IFN- $\alpha$ or IL-23. STAT1and TYK2-deficient cells displayed abnormally low levels of induction 
A

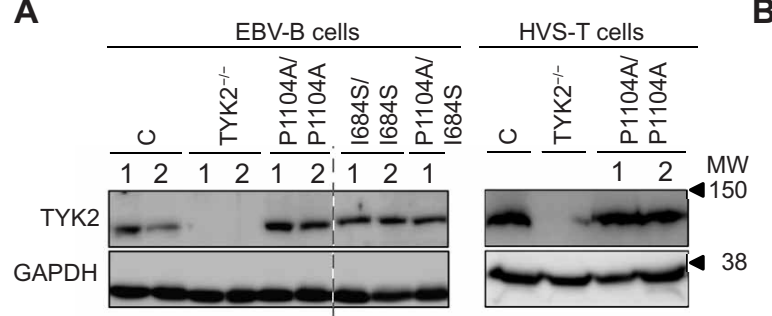

B

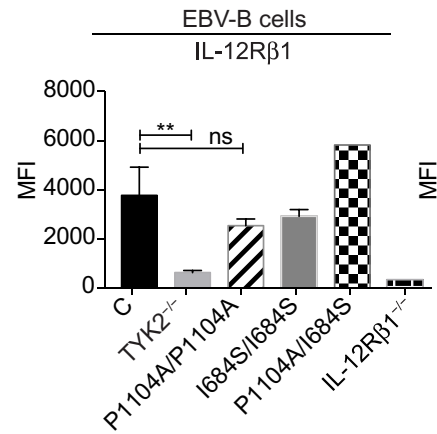

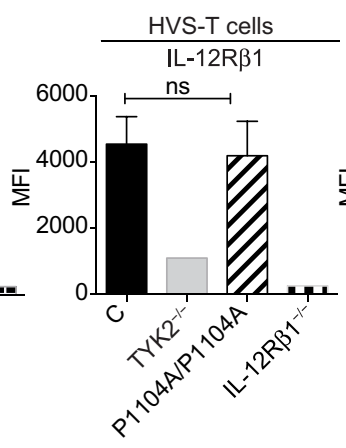

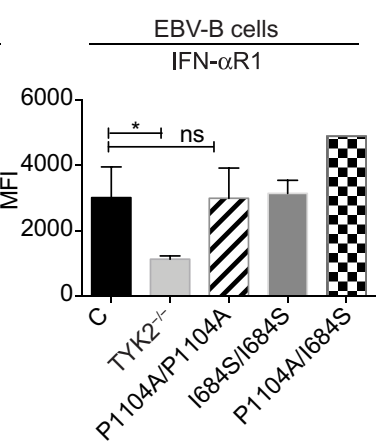

C
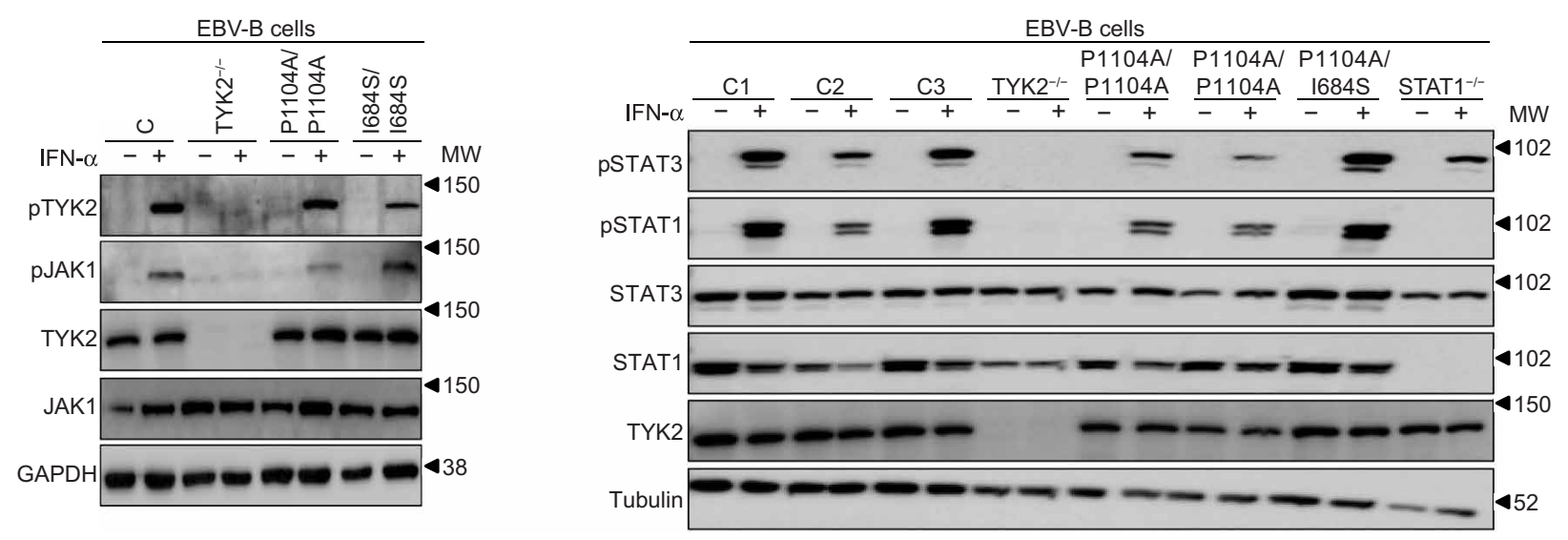

D
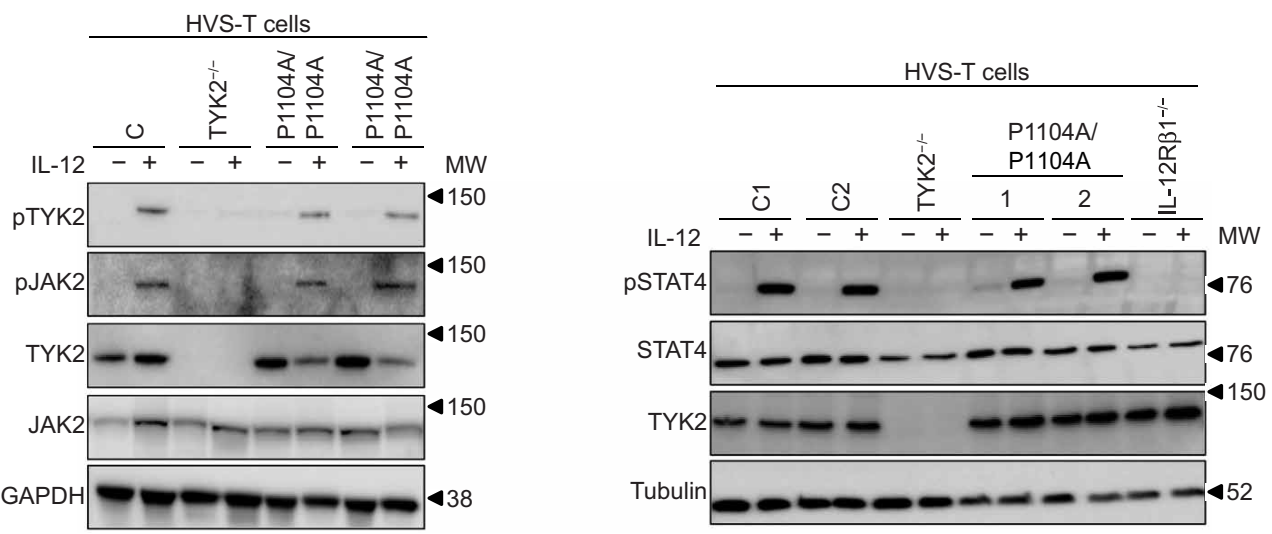

Fig. 3. Cellular responses to IFN- $\alpha$ and IL-12 in cell lines from patients. (A) TYK2 levels in EBV-B cells from two controls, two TYK2-deficient patients, two patients homozygous for TYK2 P1104A, two patients homozygous for TYK2 I684S, and a patient compound heterozygous for the P1104A/l684S TYK2 alleles, as assessed by Western blotting. (B) Levels of IL-12Rß1 in EBV-B cells and HVS-T cells and of IFN- $\alpha$ R1 in EBV-B cells from controls, TYK2-deficient patients, patients homozygous for TYK2 P1104A, patients homozygous for TYK2 1684S, and a patient compound heterozygous for P1104A/1684S TYK2 alleles, as assessed by flow cytometry. ${ }^{*} P<0.05$, ${ }^{* *} P<0.01$, two-tailed Student's $t$ test. (C and D) Phosphorylation of JAKs and STATs in EBV-B or HVS-T cells of the indicated TYK2 genotypes after stimulation with IFN- $\alpha$ (C) (pTYK2, pJAK1, pSTAT1, and pSTAT3) or IL-12 (D) (pTYK2, pJAK2, and pSTAT4), as determined by Western blotting.

for a number of IFN- $\alpha$-stimulated genes (ISGs), but no major differences were detected between controls and P1104A cells (Fig. 4C). We confirmed these results by RT-qPCR to assess the induction of two ISGs (MX1 and ISG15) in EBV-B cells and HVS-T cells stimulated with IFN- $\alpha$ (fig. S6B). RNA-seq analysis of IL-23-stimulated control EBV-B cells detected the induction of fewer target genes, SOCS3 being one of the genes most strongly induced in these conditions. IL-12R $\beta 1^{-/-}$, TYK $2^{-/-}$, and TYK2 P1104A cells displayed no response whatsoever to IL-23 (fig. S6C). Cells from a patient suffering from hyper-immunoglobulin $\mathrm{E}$ (IgE) syndrome and carrying a heterozygous dominant-negative (DN) mutation of STAT3 (STAT3-DN) had a normal pattern of target gene induction, presumably due to residual STAT3 activity, and consistent with the absence of mycobacterial infections in these patients (fig. S6C). We confirmed, by RT-qPCR, that SOCS3 mRNA was induced in control cells, but not in cells from two P1104A patients, or in TYK2- or IL-12R $\beta 1$-deficient cells, in response to IL-23 (Fig. 4D). Last, we assessed IFN- $\alpha$-mediated protection against VSV infection in primary fibroblasts from two patients homozygous for P1104A. The response of fibroblasts to IFN- $\alpha$ was indistinguishable between these patients and healthy controls, in terms of proportions of dead cells (Fig. 4E). Thus, in the cells homozygous for TYK2 P1104A tested, IFN- $\alpha$ did induce ISGs and antiviral immunity, whereas IL-23 did not induce the expression of its target genes, resulting in a phenotype as severe as that of TYK2-deficient cells.

\section{TYK2 P1 104A is catalytically inactive but can be phosphorylated}

We then analyzed the intriguing mechanism by which TYK2 P1104A selectively disrupts the IL-23-responsive pathway. As shown above, this mutant protein is well expressed and has intact scaffolding 
EBV-B cells
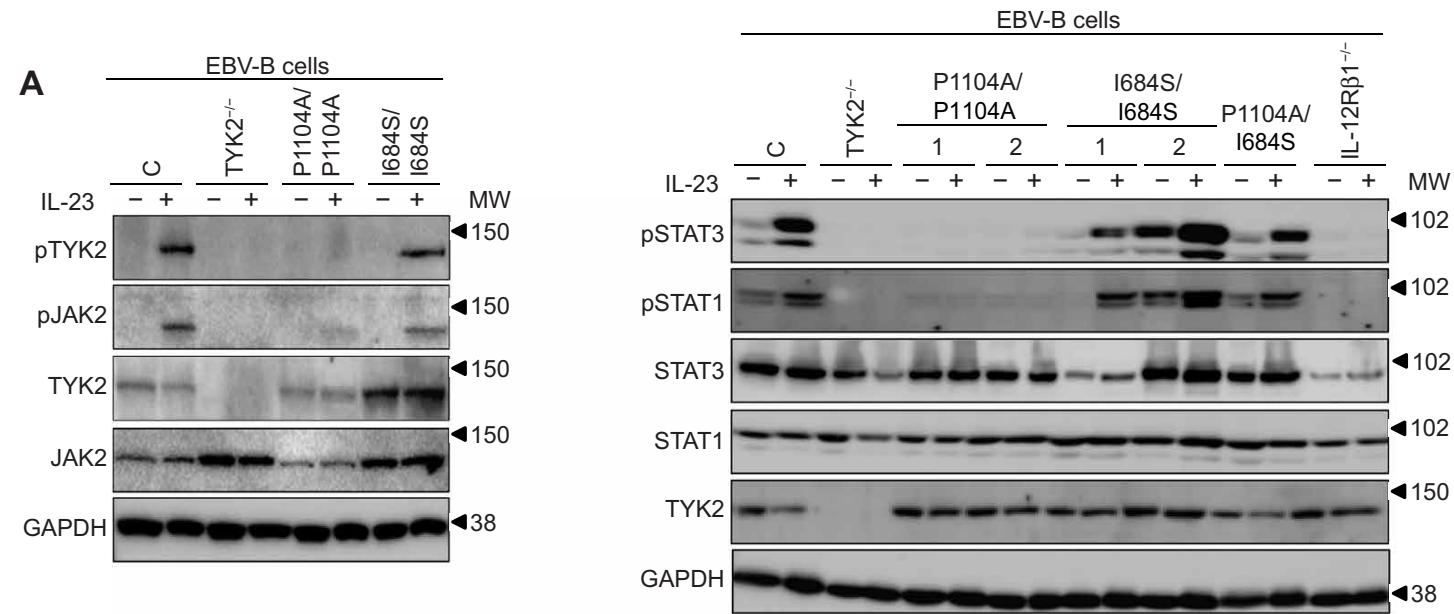

B

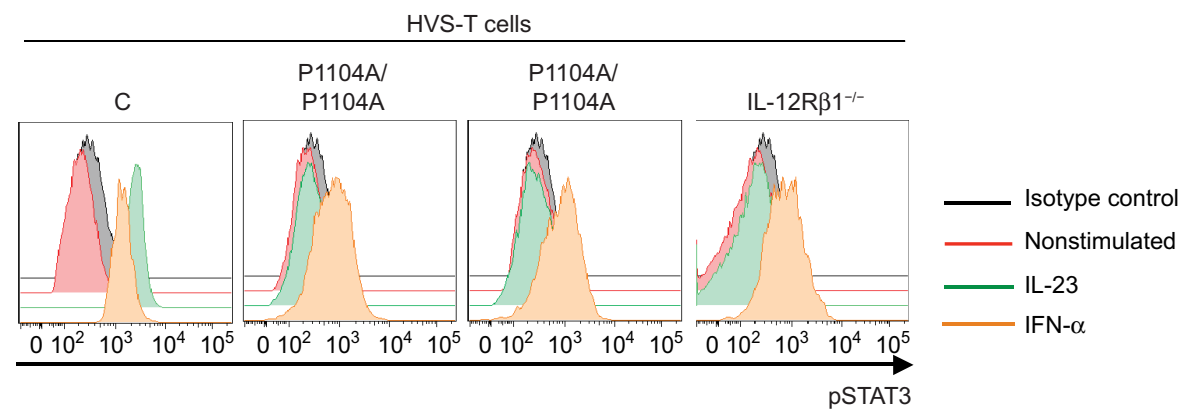

C

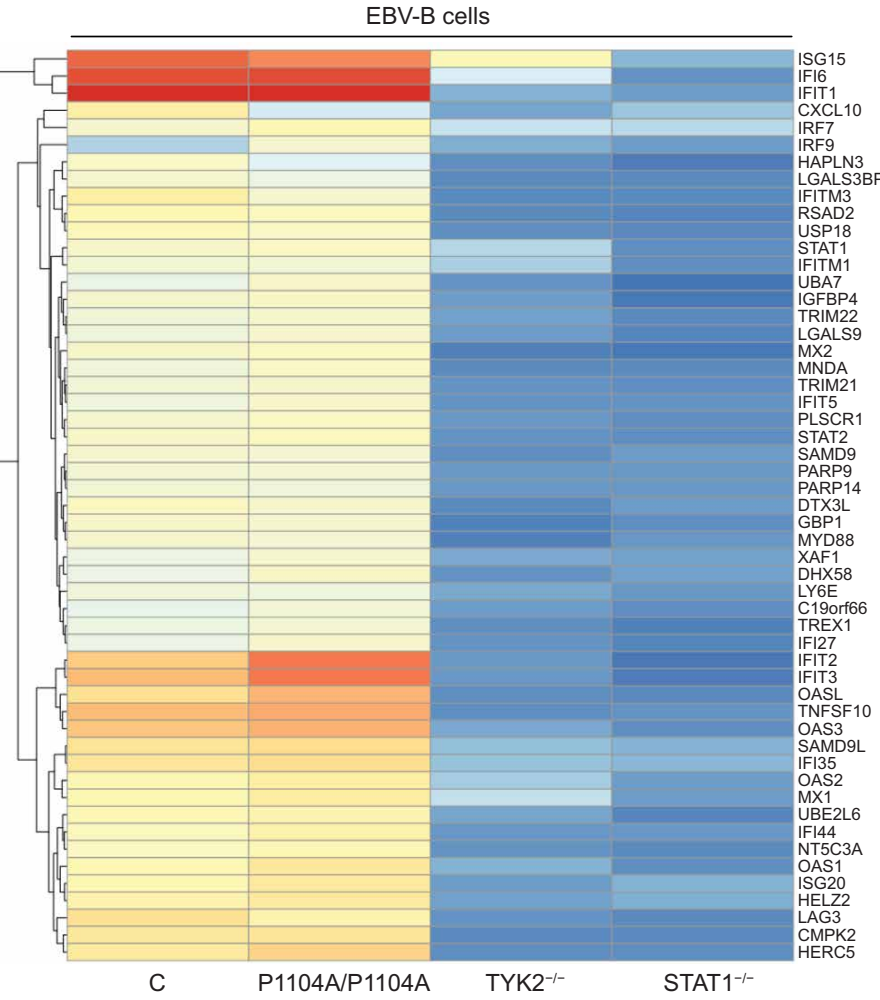

D

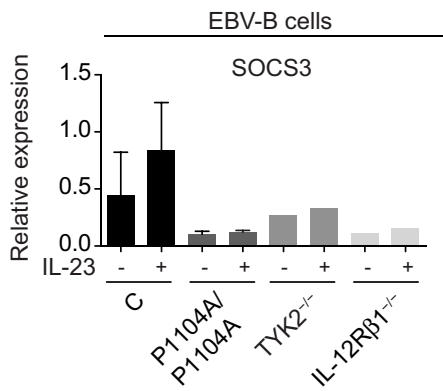

E

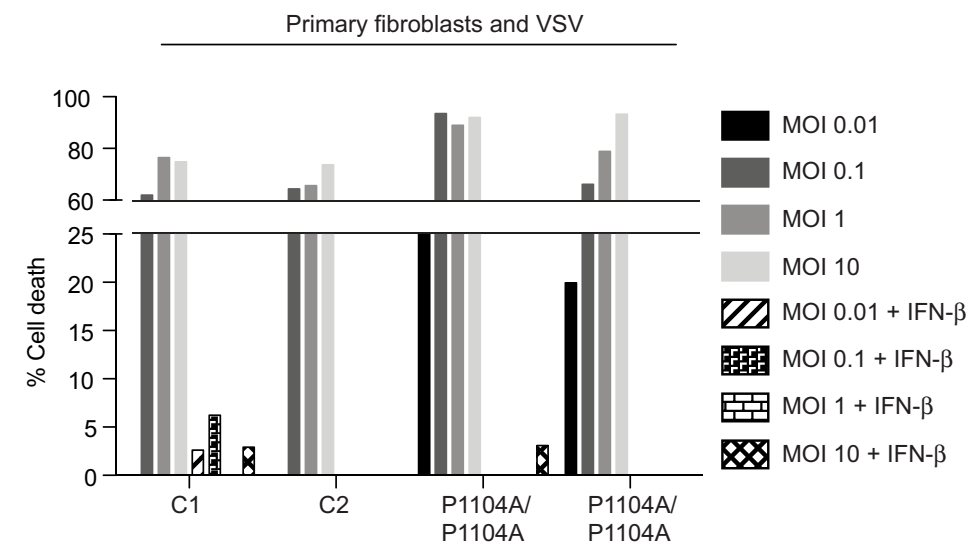

Fig. 4. Cellular responses to IL-23 and IFN- $\alpha$ in cell lines from patients. (A) Phosphorylation of JAKs and STATs in EBV-B cells carrying the indicated TYK2 genotypes after stimulation with IL-23 (pTYK2, pJAK2, pSTAT3, and pSTAT1). (B) Phosphorylation of STAT3 after stimulation with IFN- $\alpha$ or IL-23, in HVS-T cells of the indicated genotypes, as assessed by flow cytometry. (C) Expression patterns on RNA-seq of EBV-B cells stimulated with IFN- $\alpha$. The heat map represents the fold change (FC) difference in expression before and after stimulation on a $\log _{2}$ scale. Red blocks represent up-regulated genes, and blue blocks represent down-regulated genes. The genes up-regulated with an $F C$ of $\geq 2.5$, i.e., $\log _{2}(F C) \geq 1.3$, in the group of controls are shown. (D) Relative levels of SOCS3 expression in EBV-B cells after IL-23 stimulation. (E) Percentage of cell death for primary fibroblasts of the indicated genotype after VSV infection at various MOls, with and without IFN- $\beta$ pretreatment. 
activity via its docking to cytokine receptors (Figs. 2, A and B, and 3, A and B) (65). We analyzed the capacity of TYK2 P1104A to phosphorylate itself and STATs both in cells and by in vitro kinase assay. TYK2 WT, P1104A, I684S, and K930R were transiently transfected in human embryonic kidney (HEK) 293T cells, and in the absence of cytokine stimulation, baseline phosphorylation of TYK2, STAT1, STAT2, and STAT3 was assessed by Western blotting. Overexpression of TYK2 WT and I684S, unlike that of P1104A, led to phosphorylation of TYK2, STAT1, and STAT3 (fig. S7A). These data confirmed the catalytic impairment of TYK2 P1104A, in terms of both auto- and transphosphorylation (39). We then compared the abilities of TYK2 WT and P1104A to autophosphorylate and transphosphorylate recombinant STAT1 and STAT3 in an in vitro kinase assay. U1A cells were transfected with TYK2 WT or P1104A and left unstimulated or stimulated with IFN- $\beta$. TYK2 was immunoprecipitated and assayed in vitro for autophosphorylation and transphosphorylation of recombinant STAT1 and STAT3 in the presence of ATP. When purified from IFN- $\beta$-treated cells, TYK2 WT, but not P1104A, had detectable in vitro kinase activity, phosphorylating itself and recombinant STAT substrates (Fig. 5A). Notably, TYK2 P1104A immunoprecipitated from cells stimulated with IFN- $\beta$ was phosphorylated (Fig. 5A, lane 7). Thus, TYK2 P1104A cannot phosphorylate itself and STAT proteins in vitro, yet it can be phosphorylated in cells most likely by the proximal JAK1. These results render the selective impairment of the IL-23-responsive pathway even more intriguing.

\section{TYK2 P1104A and JAK2 are in proximity after IL-23 stimulation}

Our studies of lymphoid cell lines overexpressing the P1104A allele or derived from patients homozygous for P1104A revealed a normal response to IL-12 and an impaired response to IL-23. We therefore decided to study the proximal molecular events occurring in these two pathways, which have a number of components in common. The IL-12 and IL-23 pathways share a receptor chain (IL-12Rß1) and two kinases (TYK2 and JAK2) (66). Little is known about the mode of TYK2 and JAK2 activation after the binding of IL-12 and IL-23 to their heterodimeric receptors (66). The IL-23R/JAK complex has been shown to assemble in a noncanonical manner, with JAK2 binding to IL-23R much farther away from the juxtamembrane region than observed for JAK2 and IL-12R $\beta 2$ in the IL-12R/JAK complex (67). The impact of the Pro to Ala substitution on the structure of the tyrosine kinase domain of TYK2 is not known (68). We hypothesized that this substitution may perturb TYK2 folding, disrupting its proximity to JAK2 docked on IL-23R, but not IL-12R 32 . We used the Renilla luciferase protein fragment complementation assay (Rluc PCA) $(69,70)$ to test this hypothesis (Fig. 5B). Briefly, we used reporter vectors encoding TYK2 fused to the $\mathrm{N}$-terminal fragment of the Rluc protein or JAK2 fused to the C-terminal fragment of Rluc. We transiently cotransfected U1A cells previously engineered to express either IL-12 or IL-23 receptor complexes with vectors encoding both TYK2 (WT or P1104A) and JAK2 fusion proteins. We monitored bioluminescence after stimulation with IL-12 or IL-23 and the addition of benzyl-coelenterazine. JAK2 interacted with both TYK2 WT and P1104A, as shown by measurements of luciferase induction, invalidating our working hypothesis (Fig. 5B). Hence, we conclude that, in this context, the Pro to Ala substitution in TYK2 does not alter the proximity of the two enzymes docked on the IL-23 receptor complex.

\section{TYK2 catalytic activity is required for IL-23 signaling}

We then tested the specific requirement of TYK2 versus JAK2 catalytic activities for cellular responses to IL-12 and IL-23. We engineered JAK2 P1057A carrying the same Pro to Ala mutation as TYK2 P1104A (41) and JAK2 K882E as a kinase-dead negative control (71). HEK293T cells were first transfected with the different alleles. Like TYK2 P1104A, JAK2 P1057A displayed impaired autophosphorylation (fig. S7, A and B). We then used TYK2-deficient U1A cells expressing IL-12R $\beta 1$, IL-12R $\beta 2$, and IL-23R and engineered JAK2-deficient fibrosarcoma $\gamma 2 \mathrm{~A}$ cells to express IL-12R $\beta 1$, IL-12R $\beta 2$, and IL-23R. These $\gamma 2 \mathrm{~A}$ cells were transfected with JAK2 alleles, whereas U1A cells were transfected with TYK2 alleles. All cell lines were stimulated with IL-12 or IL-23. The expression of TYK2 and JAK2 and the phosphorylation of TYK2, JAK2, STAT1, and STAT3 were analyzed by Western blotting. TYK2 P1104A did not rescue phosphorylation of TYK2, JAK2, STAT3, and STAT1 in response to IL-23, but rescued response to IL-12 (Fig. 5C and fig. S7C). The phosphorylation of TYK2 P1104A by WT JAK2 in response to IL-12 was consistent with that previously seen by WT JAK1 in response to IFN- $\beta$ (Fig. $5 \mathrm{~A}$ ). These data indicated that TYK2 P1104A, unlike K930R, was impaired as an enzyme but not as a substrate. In contrast, JAK2 P1057A was phosphorylated by WT TYK2 in response to both IL-12 and IL-23 (Fig. 5C and fig. S7C), unlike JAK2 K882E, thereby leading to STAT1 phosphorylation. Together, these results suggest that IL-12 signaling can occur in the presence of only one active kinase, either JAK2 or TYK2, as long as the juxtaposed JAK can be phosphorylated. In contrast, IL-23 signaling specifically requires a catalytically active TYK2, because in this context TYK2 P1104A cannot be phosphorylated by JAK2. This may result from the different positioning of JAK2 and TYK2 within the IL-12 and IL-23 receptor complexes, which, in turn, determines the mode of activation and the specific role of each enzyme.

\section{IL-23-mediated production of IFN- $\gamma$ is impaired in TYK2 P1104A cells}

We then analyzed the cellular basis of mycobacterial diseases in the patients. Human antimycobacterial immunity is controlled by IFN- $\gamma$ (12). We analyzed the ex vivo responses of leukocytes to IL-12 and IL-23, the two TYK2-dependent cytokines that can induce IFN- $\gamma$ $(66,72-74)$. We first performed a global analysis of leukocytes, in the form of whole blood or peripheral blood mononuclear cells (PBMCs). Whole blood from healthy travel controls (control samples transported with the patients' blood), and from individuals homozygous for P1104A or I684S, or with complete TYK2 or IL-12R $\beta 1$ deficiency, were either left nonstimulated or stimulated with BCG alone or with BCG plus IL-12. IFN- $\gamma$ levels in the supernatant were determined by enzyme-linked immunosorbent assay (ELISA) 48 hours later (Fig. 6A). As a control, the blood was stimulated with BCG alone or with BCG plus IFN- $\gamma$, and the production of IL-12p40 was evaluated (fig. S8A). Blood from all five P1104A homozygous patients tested responded normally to IL-12, as reported for I684S homozygotes, but not TYK2-deficient patients (Fig. 6A). All of these patients also produced normal amounts of IL-12p40 (fig. S8A). Stimulation was also performed with BCG plus IL-23 for three P1104A patients, and IFN- $\gamma$ production was measured. No induction of IFN- $\gamma$ was detected after the addition of IL-23 to whole blood from patients homozygous for P1104A (fig. S8B). The same assay was performed with PBMCs from five P1104A patients. Five patients with DN-STAT3 deficiency, a patient with complete TYK2 deficiency 
A
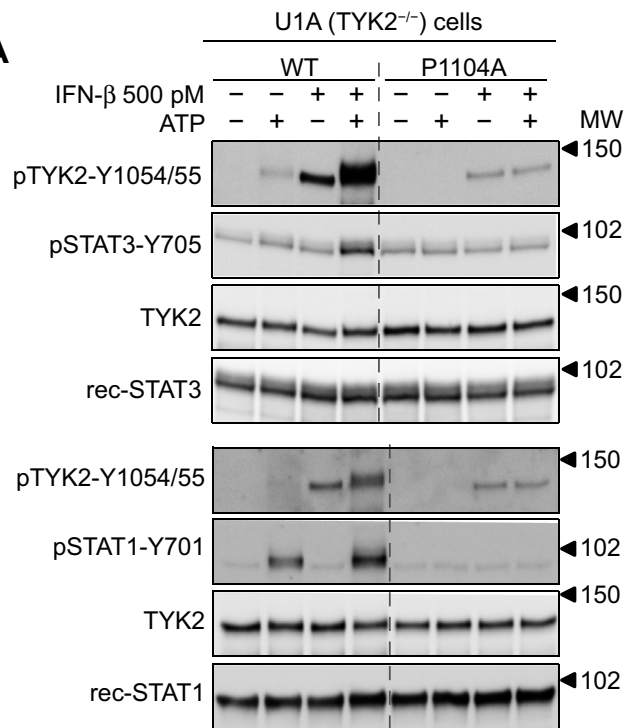

C
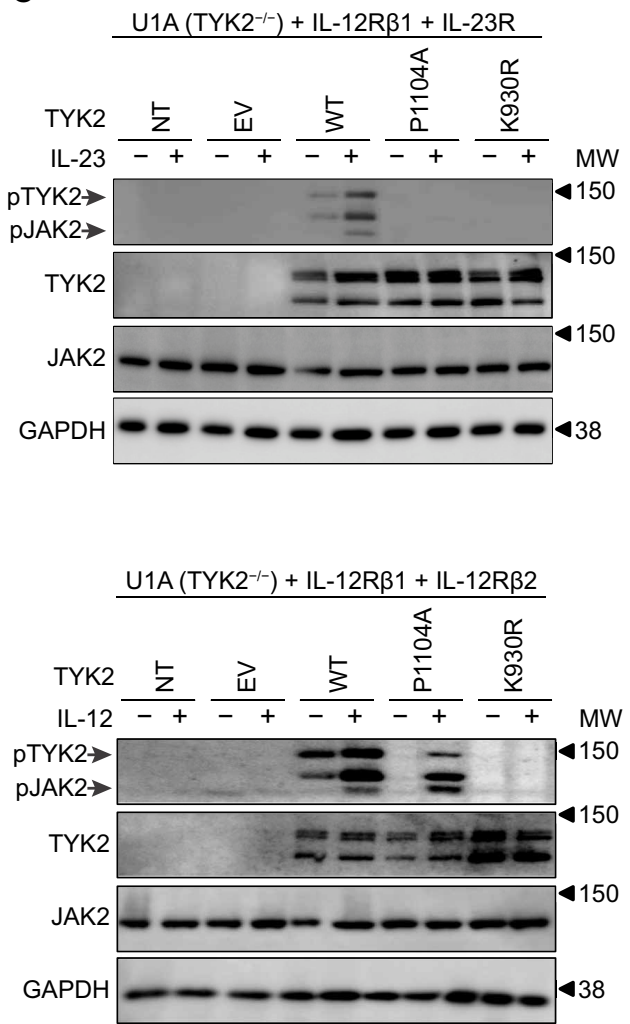

B
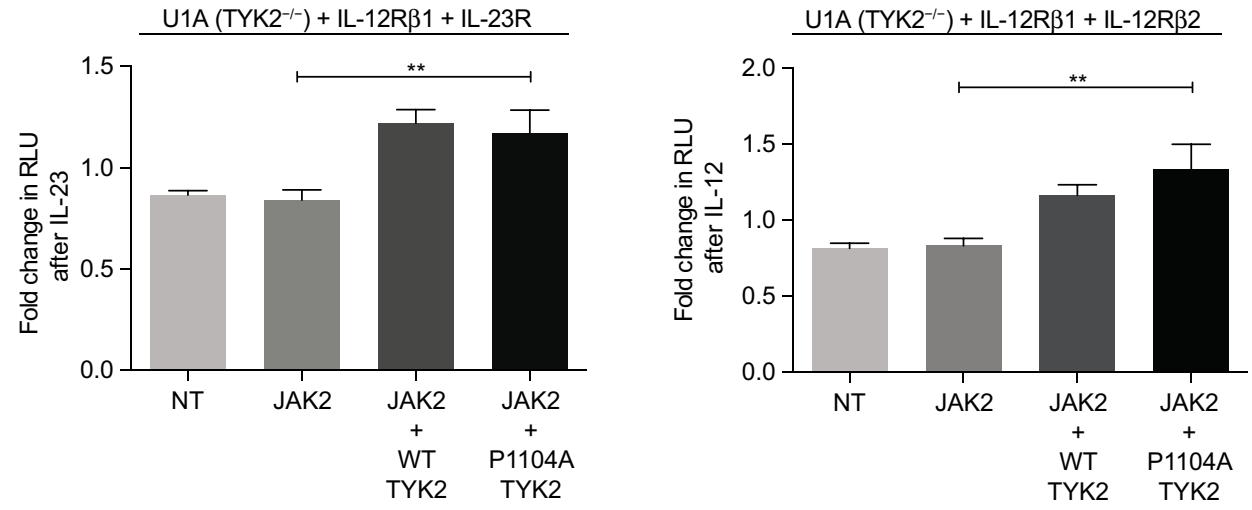

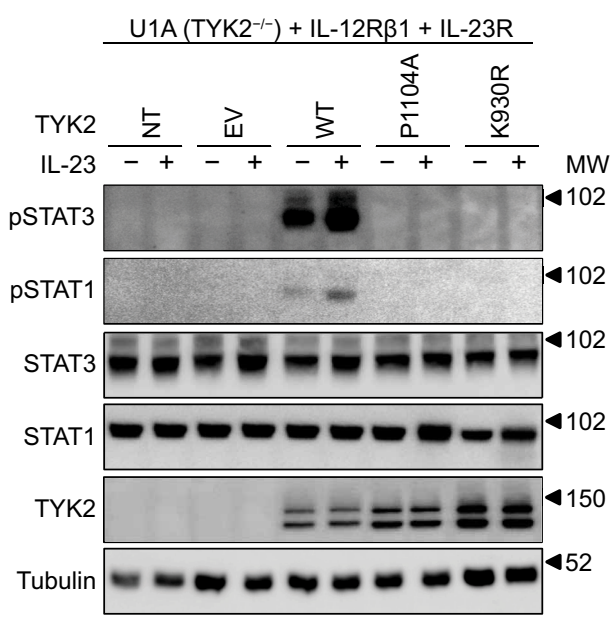

$\mathrm{U} 1 \mathrm{~A}\left(\mathrm{TYK} 2^{-1-}\right)+\mathrm{IL}-12 \mathrm{R} \beta 1+\mathrm{IL}-12 \mathrm{R} \beta 2$

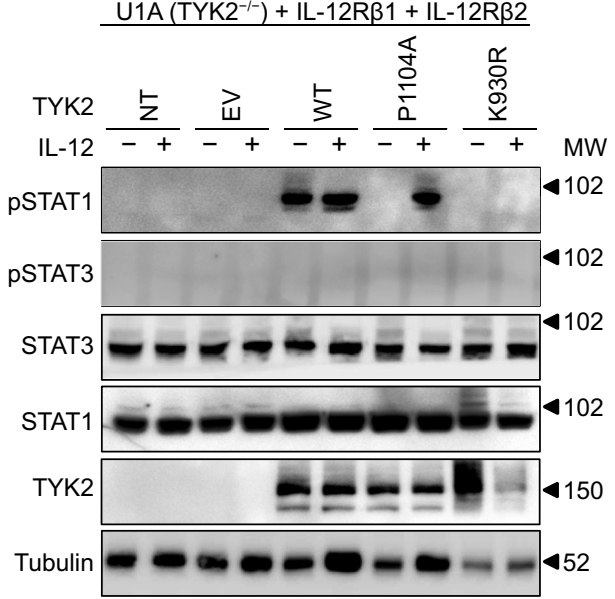

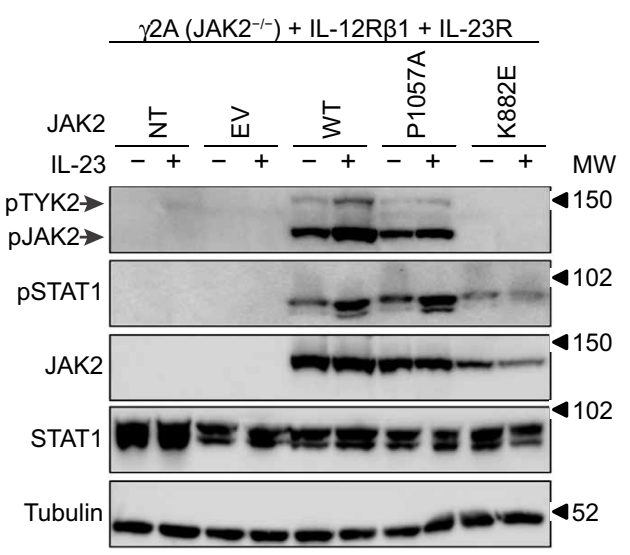

$\gamma 2 \mathrm{~A}\left(\mathrm{JAK2}^{--}\right)+\mathrm{IL}-12 \mathrm{R} \beta 1+\mathrm{IL}-12 \mathrm{R} \beta 2$

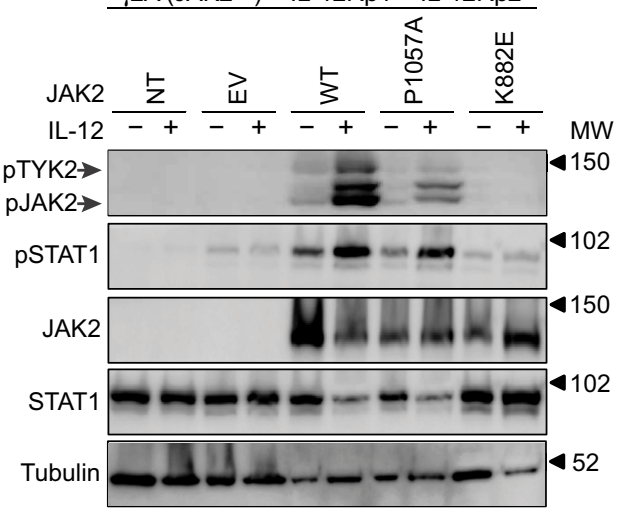

Fig. 5. Molecular mechanisms of impaired response to IL-23 by TYK2 P1104A. (A) In vitro kinase assay performed in the presence or absence of added ATP on TYK2 immunopurified from human TYK2-deficient cells (U1A) stably reconstituted with either TYK2 WT or TYK2 P1 104A. RecSTAT3 (top) or recSTAT1 (bottom) was added to the reaction mixture. The products of the reaction were analyzed by immunoblotting with antibodies specific to the two activation loop tyrosine residues of TYK2 (Tyr ${ }^{1054-1055}$ ), phospho-STAT1 $\left(\mathrm{Tyr}^{701}\right.$ ), or phospho-STAT3 $\left(\mathrm{Tyr}^{705}\right.$ ). (B) Fold change in Renilla luciferase (RLU) after stimulation with IL-23 (left) or IL-12 (right) in TYK2 ${ }^{-/-}$cells stably reconstituted with IL-12Rß1 and IL-23R (left) or IL-12Rß1 and IL-12Rß2 (right). Cells were left untransfected, or were transfected with JAK2 and TYK2 fused to Rluc fragments, for the detection of interactions after stimulation. The TYK2 used was either WT or P1104A. (C) Phosphorylation of JAK2, TYK2, STAT1, and STAT3 after stimulation with IL-12 and IL-23 in TYK2 ${ }^{-/-}$and JAK2 ${ }^{-/-}$fibrosarcoma cells reconstituted with IL-12R $\beta 1$, IL-12R $\beta 2$, and IL-23R. TYK2 ${ }^{-/}$cells were transfected with WT, P1104A, or K930R TYK2, and JAK2 ${ }^{-1-}$ cells were transfected with WT, P1057A, or K882E JAK2. 
A

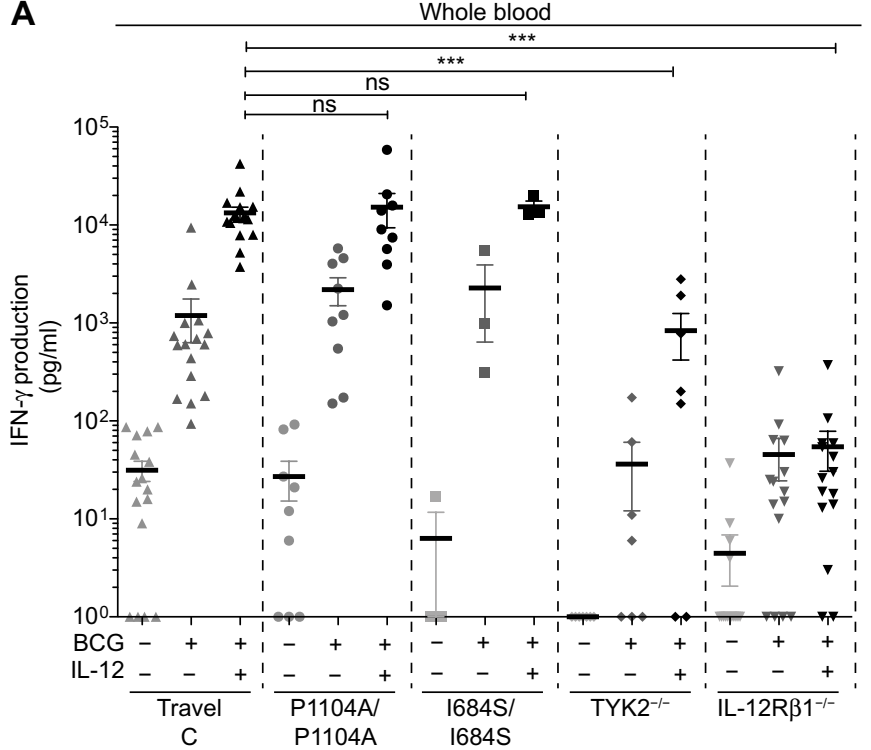

C
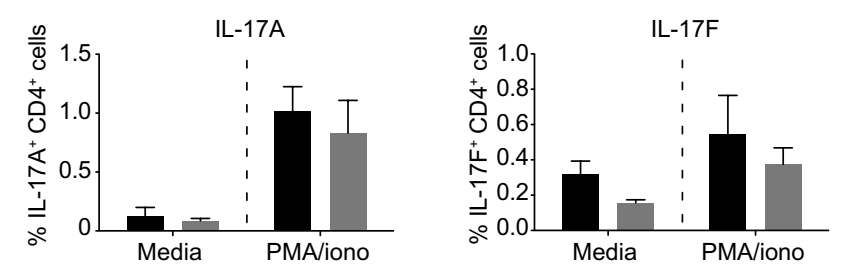

B
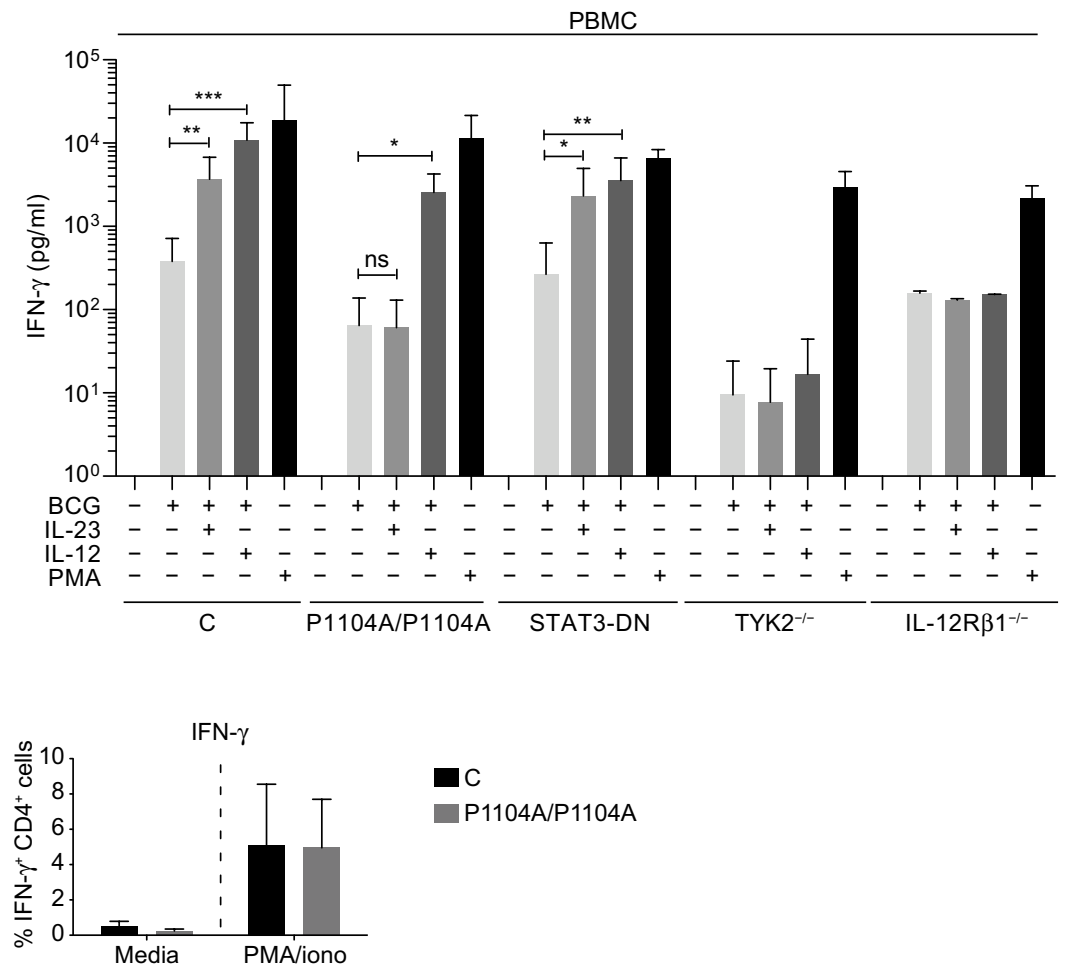

- $\mathrm{C}$

P1104A/P1104A

D
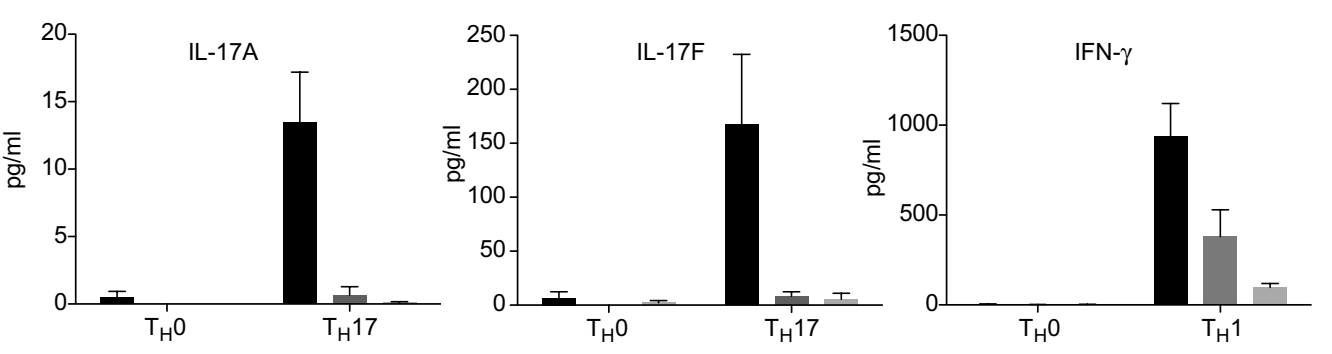

ac

P1104A/P1104A

TYK2 $2^{-1-}$

E
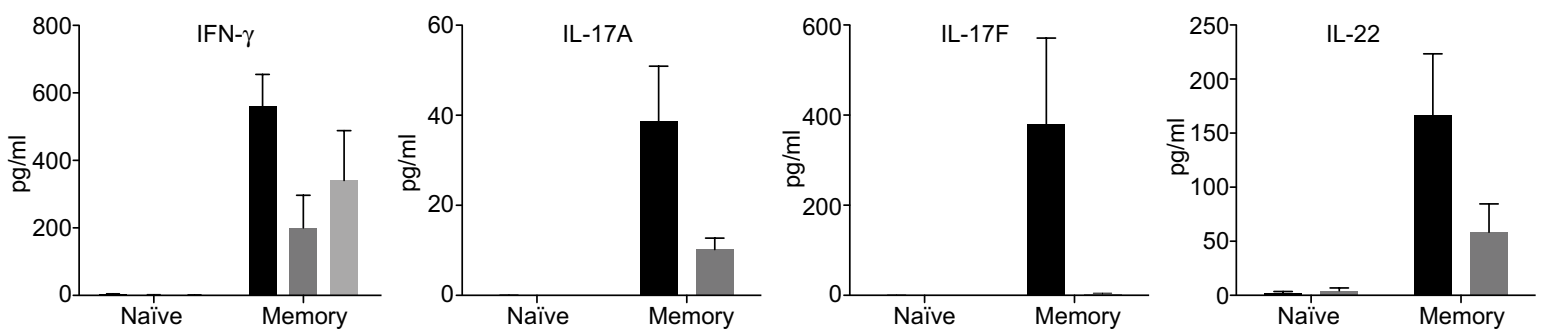

C

- TYK2 ${ }^{-1-}$

Fig. 6. Analysis of primary cells from patients. (A) ELISA analysis of IFN- $\gamma$ levels in whole blood after stimulation with BCG, or BCG plus IL-12, in travel controls, TYK2-deficient and IL-12Rß1-deficient patients, and patients homozygous for the P1104A or 1684S TYK2 alleles. ${ }^{*} P<0.05,{ }^{* *} P<0.01,{ }^{* * *} P<0.001$, two-tailed Student's $t$ tests. (B) Production of IFN- $\gamma$ from PBMCs stimulated with BCG, BCG plus IL-12, BCG plus IL-23, or PMA plus ionomycin (PMA) in healthy controls, homozygous TYK2 P1104A patients, hyper-lgE patients with heterozygous STAT3 mutations (STAT3-DN), and patients with complete TYK2 and IL-12Rß1 deficiencies, as determined by ELISA. (C) Percentages of IL-17A-, IL-17F-, and IFN- $\gamma$-positive CD4 ${ }^{+} T$ cells after the stimulation of PBMCs from healthy controls and patients homozygous for TYK2 P1 104A with PMA plus ionomycin. (D) In vitro differentiation of naïve $\mathrm{CD}^{+} \mathrm{T}$ cells from healthy controls, patients homozygous for P1104A TYK2 alleles, and patients with TYK2 deficiency, after culture under $T_{H} 17$ (with IL-23) or $T_{H} 1$ (with IL-12) polarizing conditions, as determined by assessments of the induction of IL-17A/F and IFN- $\gamma$ secretion, respectively. (E) Production of IFN- $\gamma$, IL-17A, IL-17F, and IL-22 by naïve and memory CD4 ${ }^{+}$T cells from healthy controls, patients homozygous for P1104A TYK2, and TYK2-deficient patients, stimulated with TAE beads for 5 days.

(tested twice), and two patients with complete IL-12R $\beta 1$ deficiency were used as controls (Fig. 6B). Like patients with complete TYK2 and IL-12R $\beta 1$ deficiencies, P1104A homozygotes did not respond to IL-23, in terms of IFN- $\gamma$ production, as shown by comparison with healthy controls. Cells from DN-STAT3 patients responded normally, consistent with the absence of susceptibility to mycobacterial disease in these patients (75). This lack of susceptibility may result from residual STAT3 activity, the involvement of another 
STAT, or both. TYK2 P1104A patients thus displayed impaired IL-23-mediated IFN- $\gamma$ immunity.

\section{The production of IFN- $\gamma$ is impaired in $\mathrm{T}_{\mathrm{H}}$ cells homozygous for P1104A}

We analyzed individual T cell subsets. Consistent with the results obtained for IL-12R $\beta 1$ - and IL-23R-deficient patients reported in a companion paper (76), in both of whom the IL-23 response was completely abolished, P1104A homozygotes had higher percentages of naïve $\mathrm{T}$ cells than of effector memory $\mathrm{T}$ cells. This difference was particularly marked for the $\mathrm{CD}^{+} \mathrm{T}$ cell compartment (fig. S8C). Given the known role of human IL-23 in the development of IL-17 ${ }^{+}$ $\mathrm{CD}^{+} \mathrm{T}$ cells (77), we assessed the ex vivo production of IL-17 cytokines by PBMCs upon stimulation with phorbol 12-myristate 13-acetate (PMA) plus ionomycin by intracellular flow cytometry (Fig. 6C). Patients homozygous for P1104A, like patients with complete TYK2 deficiency (10), had normal proportions of IL-17A ${ }^{+}$and IL-17F ${ }^{+}$ $\mathrm{CD} 4{ }^{+} \mathrm{T}$ cells, probably because of residual TYK2-independent responses to IL-23 $(10,28)$, and consistent with the absence of CMC in these patients. In these conditions, the percentages of IFN- $\gamma^{+}$ $\mathrm{CD}^{+} \mathrm{T}$ cells in P1104A patients were also normal (Fig. 6C). We also analyzed the frequencies of the four different $\mathrm{CD} 4^{+}$memory $\mathrm{T}$ helper $\left(\mathrm{T}_{\mathrm{H}}\right)$ cell subsets $\left(\mathrm{T}_{\mathrm{H}} 1, \mathrm{~T}_{\mathrm{H}} 2, \mathrm{~T}_{\mathrm{H}} 17\right.$, and $\left.\mathrm{T}_{\mathrm{H}} 1^{*}\right)$, as determined by the differential expression of CCR6, CCR4, and CXCR3, in only one patient. The frequencies of $\mathrm{T}_{\mathrm{H}} 1\left(\mathrm{CXCR}^{+}{ }^{+} \mathrm{CCR} 6^{-}\right)$and $\mathrm{T}_{\mathrm{H}} 1^{*}\left(\mathrm{CXCR}^{+}{ }^{+} \mathrm{CCR} 6^{+}\right)$ cells, the main memory subsets involved in antimycobacterial immunity $(76,78)$, were found to be low (fig. S8E).

\section{The response to IL-23 is impaired in T cells homozygous for P1104A}

We then studied the capacity of naïve $\mathrm{CD}^{+}{ }^{+} \mathrm{T}$ cells from P1104A homozygotes to differentiate into $\mathrm{T}_{\mathrm{H}} 17$ cells in an IL-23-dependent manner, using $\mathrm{T}$ cell activation and expansion (TAE) beads (antibodies directed against CD2, CD3, and CD28) in addition to TGF- $\beta$ (transforming growth factor- $\beta$ ), IL-1 $\beta$, IL-6, IL-21, IL-23, anti-IL-4, and anti-IFN- $\gamma$ (79). These cells were unable to produce IL-17A/ IL-17F, consistent with the impairment of IL-23 signaling, as observed in IL-12R $\beta 1$ - and TYK2-deficient patients (Fig. 6D). Conversely, naïve $\mathrm{CD} 4^{+} \mathrm{T}$ cells from $\mathrm{P} 1104 \mathrm{~A}$ homozygotes were able to differentiate into IFN- $\gamma$-producing $\mathrm{T}_{\mathrm{H}} 1$ cells in an IL-12dependent manner (TAE beads and IL-12), like control cells and cells from IL-23R-deficient patients, but unlike cells from TYK2-, IL-12R $\beta 1$-, and IL-12R $\beta 2$-deficient patients (Fig. 6D and companion paper). We also analyzed the memory $\mathrm{CD}^{+} \mathrm{T}$ cell compartment of five P1104A patients by stimulating these cells with TAE beads. As expected, incubation with these beads resulted in lower levels of $\mathrm{T}_{\mathrm{H}} 17$ cytokines (IL-17A, IL-17F, and IL-22) being produced by TYK2 P1104A memory $\mathrm{CD} 4^{+} \mathrm{T}$ cells than memory $\mathrm{CD} 4^{+} \mathrm{T}$ cells from healthy donors (Fig. $6 \mathrm{E}$ and fig. S8D). Moreover, $\mathrm{P} 1104 \mathrm{~A}$ cells had a reduced capacity to produce IFN- $\gamma$, similar to that of IL-23R- and IL-12R $\beta 1$-deficient cells. Overall, these data reveal that P1104A homozygosity impairs IL-23, but not IL-12, responses in peripheral $\mathrm{CD} 4^{+} \mathrm{T}$ cells, as previously shown in $\mathrm{B}$ and $\mathrm{T}$ cell lines. They also show that $\mathrm{CD} 4^{+} \mathrm{T}$ cells of P1104A homozygotes have impaired IFN- $\gamma$ production, due to their very weak response to IL-23, accounting for the susceptibility to MSMD or primary tuberculosis. Paradoxically, the TYK2-dependent response to IL-23 that is disrupted by P1104A is essential for antimycobacterial IFN- $\gamma$ immunity, but seems to be redundant for anti- fungal IL-17 immunity, given the absence of Candida infection in the patients described here.

\section{The frequencies of MSMD and tuberculosis differ in P1104A homozygotes}

The clinical infectious presentation of the 10 P1104A homozygotes was restricted to mycobacterial disease. The penetrance for infections due to weakly virulent mycobacteria (MSMD) is probably lower than that for primary tuberculosis after exposure to these microbial species, as inferred from (i) the lower ethnicity-adjusted ORs estimated for MSMD ( 23) than for primary tuberculosis ( 89); (ii) the respective frequencies of MSMD (about 1/50,000 BCG-vaccinated individuals, as inferred from the equal proportions of idiopathic BCG-osis, and severe combined immunodeficiency, the frequency of which has been determined in several human populations) (80) and primary tuberculosis in human populations (about 5 to $7 \%$ of infected individuals) $(9,81$ ), reflecting the difference in virulence between the causal mycobacteria; (iii) the higher level of exposure worldwide to BCG and environmental mycobacteria than to M. tuberculosis; and (iv) the biological impact of P1104A homozygosity (severely impaired but not abolished response to IL-23 and normal response to IL-12) relative to that of IL-12R $\beta 1$ deficiency (abolished responses to both IL-12 and IL-23) $(20,25)$. The vast majority of P1104A homozygotes worldwide would be predicted to be asymptomatic, particularly if living in areas of low endemicity for tuberculosis. Most of the patients with symptoms would be predicted to suffer from tuberculosis, with only a minority presenting MSMD. Our own observation of three patients with MSMD and seven patients with tuberculosis reflects an ascertainment bias, because the proportion of all patients worldwide included in our database is much higher for MSMD than for tuberculosis. The proportions of P1104A homozygotes with these two diseases were similar in our study: MSMD $(3 / 464=0.6 \%)$ and tuberculosis $(7 / 453=1.5 \%)$. Because tuberculosis is much more common than MSMD by at least two orders of magnitude (and probably around three orders of magnitude in highly endemic areas), it would be expected to be, by far, the most frequent disease in symptomatic P1104A homozygotes.

\section{The penetrance of $\mathrm{P} 11$ 104A homozygosity is high for tuberculosis}

A more formal estimation of the penetrance of P1104A homozygosity for tuberculosis (or MSMD), denoted $\mathrm{F}_{\text {TYK2TB }}$ (or $\mathrm{F}_{\text {TYK2MSMD }}$ for MSMD), can be calculated from the observed ORs, and the probability of developing tuberculosis (or MSMD) for those infected who are not P1104A homozygotes, denoted $\mathrm{F}_{\mathrm{TB}}$ (or $\mathrm{F}_{\mathrm{MSMD}}$ ), is detailed in Supplementary Materials and Methods. Because P1104A homozygotes account for only a small proportion of tuberculosis (or MSMD) cases (see below), $\mathrm{F}_{\mathrm{TB}}$ (or $\mathrm{F}_{\mathrm{MSMD}}$ ) can reasonably be inferred from the general risk of primary tuberculosis (or MSMD) for an infected individual indicated above [see (ii)]. For P1104A, we used the frequency observed in North Africa (1.8\%), which is approximately the same as the mean frequency in the regions in which our tuberculosis and MSMD patients were living. For an $\mathrm{F}_{\mathrm{TB}}$ value of 5\% and an OR of 89.31 (14.7 to 1725), the estimated $\mathrm{F}_{\text {TYК2TB is }}$ $82 \%$ (44 to $99 \%$ ) and the proportion of tuberculosis cases due to $\mathrm{P} 1104 \mathrm{~A}$ homozygotes is $0.5 \%(0.3$ to $0.6 \%)$ for a $\mathrm{P} 1104 \mathrm{~A}$ minor allele frequency (MAF) of $1.8 \%$. For an $\mathrm{F}_{\mathrm{MSMD}}$ value of $0.002 \%$ (corresponding to a prevalence of MSMD of $1 / 50,000)$ and an OR of 


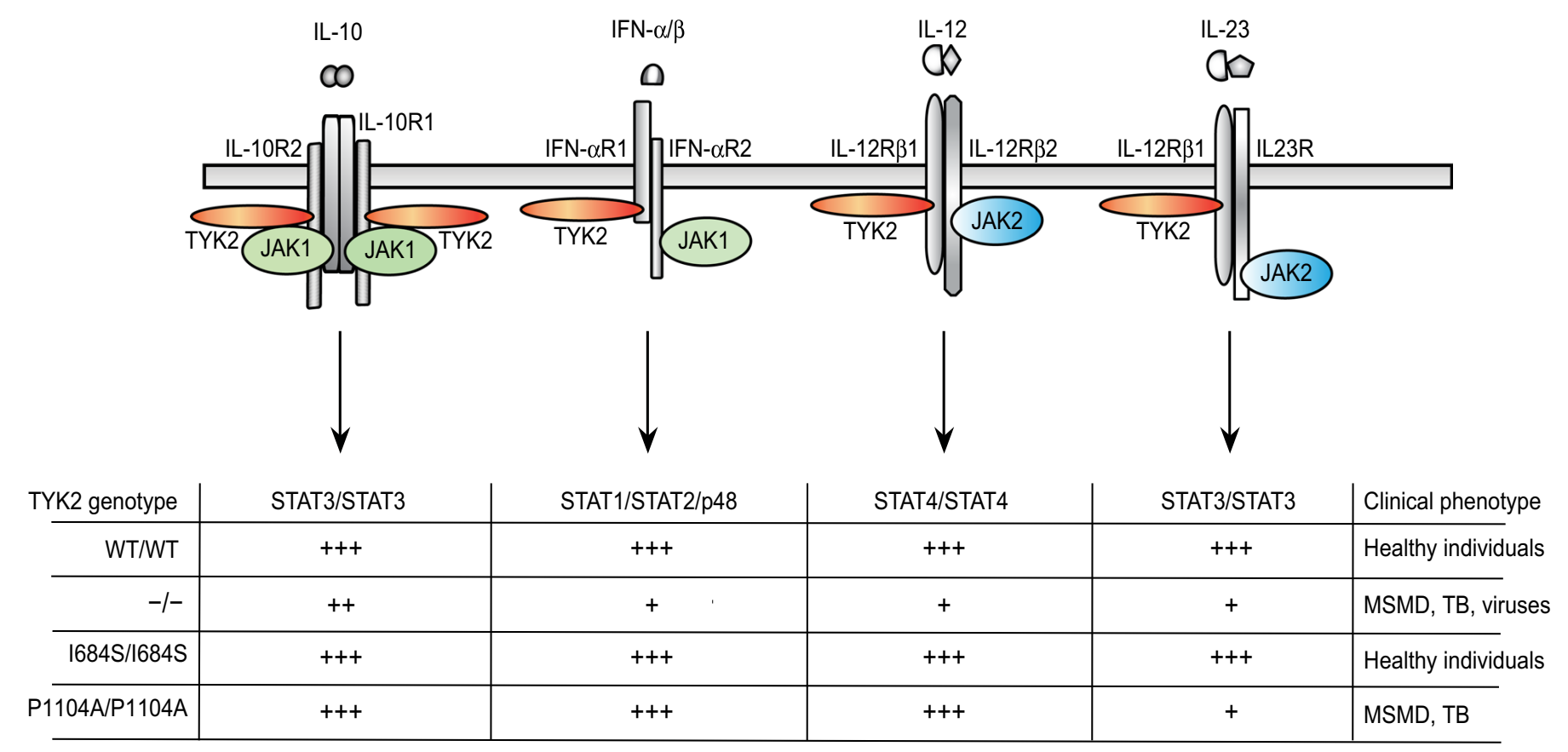

Fig. 7. Schematic representation of TYK2-dependent signaling pathways. The cytokines, receptors, and JAK and STAT complexes formed are indicated. A summary of the functionality of each pathway is provided for the various genotypes: TYK2 WT/WT, TYK2 ${ }^{-1-}$, TYK2 I684S/I684S, and TYK2 P1104A/P1104A. The main STAT-containing complexes are shown. Other complexes include STAT1/STAT1 in response to IL-10, IL-12, IL-23, and IFN- $\alpha / \beta$ and STAT3/STAT3 and STAT4/STAT4 in response to IFN- $\alpha / \beta$. The symbol +++ indicates that the pathway is functional and optimal (corresponding to WT TYK2). The symbol ++ indicates that the function of the pathway is decreased without overt clinical implications. The symbol + means that the function of the pathway is impaired, but not completely abolished because of TYK2-independent residual signaling, and can bear clinical consequences (except for IL-10). The clinical phenotypes of individuals homozygous for the WT, P1104A, and I684S TYK2 alleles are indicated on the right.

23.53 ( 2 to 483 ), the estimated $\mathrm{F}_{\text {TYK2MSMD }}$ is $0.05 \%(0.004$ to $1 \%)$ and the proportion of MSMD cases due to P1104A homozygosity is $0.7 \%$ ( 0.06 to $15 \%)$ for the same MAF (1.8\%). This proportion is close to that estimated for tuberculosis here $(0.5 \%)$. The CIs associated with these estimates are large, but these findings clearly indicate that the penetrance of P1104A homozygosity is high for tuberculosis in endemic areas (about 80\%), certainly much higher than that for MSMD in areas in which BCG vaccination is mandatory (about $0.05 \%$ ). Conversely, the penetrance of IL-12R $\beta 1$ deficiency for MSMD is higher, estimated at about $80 \%$ in adults (20), consistent with the observation that most of these patients present with MSMD, whereas most patients homozygous for P1104A present with tuberculosis. Consistently, homozygosity for TYK2 P1104 is predicted to account for about $0.5 \%$ of cases of primary tuberculosis in areas of endemic disease, such as Morocco, whereas AR TYK2 and IL-12R $\beta 1$ complete deficiency are much less common genetic etiologies.

\section{DISCUSSION}

In conclusion, homozygosity for TYK2 P1104A confers a predisposition to severe mycobacterial diseases, including MSMD and, more frequently, primary tuberculosis. Several genome-wide association studies have shown that homozygosity for TYK2 P1104A has a strong protective effect (ORs ranging from 0.1 to 0.3 ) against various autoinflammatory or autoimmune conditions (41). Our findings suggest a mechanism based on selective or preferential impairment of the IL-23 responsive pathway (Fig. 7). In other experimental conditions, TYK2 P1104A also impaired IL-12 and IFN$\alpha / \beta$ responses (41). These findings are unlikely to be physiologically relevant, as illustrated by the viral infections seen in TYK2-deficient but not P1104A-homozygous patients (10). The higher incidence of inflammatory conditions in modern adults than in earlier human populations may result partly from the negative selection of alleles, such as $\mathrm{P} 1104 \mathrm{~A}$, that impair protective immunity to primary infection by dampening inflammatory responses (82-84). In this respect, this study should also help to delimit the potential beneficial and adverse effects of pharmaceutical TYK2 inhibitors (85-87).

The P1104A TYK2 variant selectively disrupts IL-23-dependent antimycobacterial IFN- $\gamma$ immunity, accounting for the susceptibility of homozygotes to mycobacteria. The gradual decline of the P1104A allele in the European continent, which requires further investigation using more ancient DNA samples from different geographic locations and epochs, suggests that tuberculosis has been continuously endemic from the Neolithic until the middle of the 20th century (56). Given the current MAF for P1104A of $4.2 \%$ in European populations, there are about $1 / 600(1.7 / 1000)$ homozygotes in Europe and populations of European descent, making P1104A TYK2 homozygosity an AR condition almost as frequent in Europeans as hemochromatosis $(3 / 1000)$ and more common than cystic fibrosis $(0.4 / 1000)$ and $\alpha 1$ anti-trypsin deficiency (0.4/1000). Our findings are thus important and support a revision of the genetic architecture of human diseases, because tuberculosis is much more common than these three other AR disorders. They suggest that common infections, and more generally common human diseases, may be caused by relatively common AR disorders in a small but not negligible proportion of patients.

The clinical penetrance of P1104A homozygosity for mycobacterial disease in Europe is now particularly low, because few Europeans are exposed to BCG, and even fewer to M. tuberculosis. The vast majority of present-day European homozygotes are apparently 
healthy $(41,42)$. Genetic testing before travels into endemic areas may, however, be warranted. Homozygosity for P1104A is more likely to be symptomatic elsewhere, as illustrated by the fact that 9 of our 10 patients are from geographic regions outside Europe, in continents on which BCG vaccination is mandatory and tuberculosis is endemic. Between $1 / 10,000$ and $1 / 1000$ individuals are homozygous in endemic regions of the world (other than East Asia), where P1104A TYK2 is likely to define a strictly recessive but relatively common etiology of severe primary tuberculosis (about $0.5 \%$ of cases). This observation has important clinical implications, because injections of recombinant IFN- $\gamma$ would probably be beneficial in these patients, as it is in patients with IL-12R $\beta 1$ deficiency $(12,19,88)$.

\section{MATERIALS AND METHODS Study design}

We studied the contributions of two common TYK2 missense variants, I684S and P1104A, to predisposition to mycobacterial diseases. We screened our WES database including 463 patients with MSMD, 454 with tuberculosis, and 2835 with non-mycobacterial infections used as controls, as well as the WES data of the 2504 from the 1000 Genomes Project (a total of 5339 controls). We tested the association of the two TYK2 variants with MSMD and tuberculosis using a logistic regression model including the first three principal components of the PCA to account for the ethnic heterogeneity of the cohorts. After adjusting for ethnicity, we found a strong enrichment of $\mathrm{P} 1104 \mathrm{~A}$ homozygotes in the tuberculosis cohort $\left(P=8.37 \times 10^{-8}\right.$; OR, $89.31 ; 95 \% \mathrm{CI}, 14.7$ to 1725$)$ and, to a lesser extent, in the MSMD cohort $\left(P=3.27 \times 10^{-3}\right.$; OR, $23.53 ; 95 \%$ CI, 2.9 to 483 ). We analyzed the occurrence of negative selection acting on the two TYK2 variants by testing whether their frequency in Europeans has decreased more than other variants that were in the same frequency range 4000 years ago. We tested the impact of both TYK2 variant in both transduced cell lines and homozygous patients' cell lines in terms of cellular responses to IL-10, IL-12, IL-23, and IFN- $\alpha / \beta$. We also tested the patient's primary leukocytes.

\section{Ethics statement}

This study was conducted in accordance with the Helsinki Declaration, with written informed consent obtained from the patients' families. Approval for this study was obtained from the French Ethics Committee "Comité de Protection des Personnes," The French National Agency for Medicine and Health Product Safety (ANSM) and the Institut National de la Santé et de la Recherche Médicale in France, and the Rockefeller University Institutional Review Board (IRB), New York, USA.

\section{Whole-blood activation experiments}

Venous blood samples from controls and patients were collected into heparin-containing tubes and processed according to a modified version of the protocol described by Feinberg et al. (89). Briefly, they were diluted 1:2 in RPMI 1640 (Gibco BRL) and supplemented with penicillin $(100 \mathrm{U} / \mathrm{ml})$ and streptomycin $(100 \mu \mathrm{g} / \mathrm{ml})(\mathrm{Gibco} B R L)$. We then dispensed $5 \mathrm{ml}$ of each diluted blood sample into each of five wells ( $1 \mathrm{ml}$ per well) of a 48 -well plate (Nunc). These samples were incubated for 48 hours at $37^{\circ} \mathrm{C}$ under an atmosphere containing $5 \% \mathrm{CO}_{2} / 95 \%$ air, under three different sets of activation conditions: with medium alone, with live BCG (Mycobacterium bovis BCG, Pasteur substrain) at a multiplicity of infection (MOI) of 20 BCG cells per leukocyte, with BCG plus recombinant human (rh) IL-23 (100 ng/ml; R\&D Systems), with BCG plus rhIL-12 (20 ng/ml; R\&D Systems), and with PMA (40 ng/ml; Sigma-Aldrich) plus ionomycin $\left(10^{-5} \mathrm{M}\right.$; Sigma-Aldrich). ELISA was then performed on the collected supernatants, with the human IFN- $\gamma$ ELISA Kit (Ready-SET-Go! from eBioscience or PeliPair from Sanquin), in accordance with the manufacturer's instructions. All venous blood samples were collected in accordance with the IRB protocols of The Rockefeller University, New York.

\section{Plasmids and retroviral transduction of $T$ and $B$ cell lines}

T cell lines (HVS-T) and EBV-transformed lymphoblastoid cell lines (EBV-B cells) were generated by infecting PBMCs from healthy controls or patients with HVS or EBV, as previously described (10). A retroviral vector expressing WT TYK2 was generated by inserting the TYK2 sequence from pMSCVpuro retrovirus (Takara Bio Inc.) into the pLZRS-IRES- $\triangle$ NGFR vector, which contains a puromycin resistance cassette (60). The WT TYK2 allele used here contains a mutation at position 1016, P1016S. Various alleles of TYK2 (P1104A, I684S, and K930R) were then generated by site-directed mutagenesis, with specific primers and the PfuUltra II Hotstart PCR Master Mix (Agilent Technologies), according to the manufacturer's instructions. The plasmids were used to transfect Phoenix-A packing cells to generate retroviral particles carrying each allelic variant. Briefly, $10 \mu \mathrm{g}$ of vector was used to transfect Phoenix-A packaging cells in the presence of Opti-MEM + GlutaMAX (Gibco) and X-tremeGENE 9 (Roche), according to the manufacturer's instructions. Positively transfected cells were selected with puromycin (Gibco) at a concentration of $2 \mu \mathrm{g} / \mathrm{ml}$ until all the cells were positive for the surface expression of $\triangle \mathrm{NGFR}$, as assessed by fluorescence-activated cell sorting with Alexa Fluor 647 anti-NGFR staining (BD Pharmingen). The Phoenix-A cell culture was then split in two flasks, to which puromycin-free medium was added. After 24 hours, the supernatant was collected and retroviral particles were concentrated with Retro-X Concentrator (Clontech) according to the manufacturer's instructions. One million HVS-T cells were mixed with retroviruscontaining supernatant in a total volume of $2 \mathrm{ml}$. After incubation for 24 hours, $200 \mu \mathrm{l}$ of fetal calf serum was added and the cells were allowed to grow for a further 4 days. Transduced cells were positively purified by magnetic-activated cell sorting with an antiNGFR-biotin antibody and an anti-biotin antibody conjugated with magnetic beads (Miltenyi Biotec) according to the manufacturer's protocol.

\section{Cell culture and stimulation}

EBV-B cells were cultured in RPMI (Gibco) supplemented with $10 \%$ fetal bovine serum (FBS) (Invitrogen). HVS-T cells were cultured in a 1:1 mixture (by volume) of RPMI and Panserin 401 (PAN Biotech) supplemented with 10\% FBS, GlutaMAX (350 $\mu \mathrm{g} / \mathrm{ml}$; Gibco), gentamicin (0.1 mg/ml; Gibco), and rhIL-2 (20 IU/ml; Roche). The cells were then starved for 2 hours by incubation in serum-free RPMI. The cells were then left unstimulated or were stimulated with rhIFN- $\alpha 2 \mathrm{~b}\left(3.2 \times 10^{4} \mathrm{IU} / \mathrm{ml}\right.$; Schering), rhIL-23 (100 ng/ml; R\&D Systems), rhIL-12 (20 ng/ml; R\&D Systems), or rhIL-10 (50 ng/ml; PeproTech) for $5 \mathrm{~min}$ to assess the phosphorylation of TYK2, JAK1, or JAK2 and for $30 \mathrm{~min}$ to assess the phosphorylation of STAT1, STAT3, or STAT4. A dose-response experiment was performed on EBV-B cells, with different concentrations of rhIL-23 ranging from 
50 to $200 \mathrm{ng} / \mathrm{ml}$ and a stimulation time of $30 \mathrm{~min}$. A kinetic analysis of the response to IL-23 was also performed, in which EBV-B cells were stimulated with rhIL-23 $(100 \mu \mathrm{g} / \mathrm{ml})$ for $0,1,3$, and 5 hours. For RT-qPCR, cells were stimulated for 6 hours with IL-10 $(50 \mathrm{ng} / \mathrm{ml})$, IL-23 $(100 \mathrm{ng} / \mathrm{ml})$, or IFN- $\alpha\left(10^{5} \mathrm{IU} / \mathrm{ml}\right)$. For the RNA-seq experiment, cells were stimulated for 8 hours with IL-23 $(100 \mathrm{ng} / \mathrm{ml})$ or IFN- $\alpha\left(10^{5} \mathrm{IU} / \mathrm{ml}\right)$.

\section{Western blotting}

Total protein was extracted from EBV-B or HVS-T cells in a lysis buffer containing $1 \% \mathrm{NP}-40,20 \mathrm{mM}$ tris- $\mathrm{HCl}$ (pH 7.4), $140 \mathrm{mM}$ $\mathrm{NaCl}, 2 \mathrm{mM}$ EDTA, and $50 \mathrm{nM} \mathrm{NaF}$ supplemented with $100 \mathrm{mM}$ orthovanadate, $200 \mathrm{mM}$ phenylmethylsulfonyl fluoride, $1 \%$ aprotinin, pepstatin $(1 \mathrm{mg} / \mathrm{ml})$, leupeptin $(1 \mathrm{mg} / \mathrm{ml})$, and antipain $(1 \mathrm{mg} / \mathrm{ml})$. Protein extracts were separated by SDS-polyacrylamide gel electrophoresis, and the resulting bands were electroblotted onto polyvinylidene difluoride membranes. The blots were incubated for 1 hour with a blocking solution consisting of tris-buffered saline (TBS), $0.01 \%$ Tween 20 (Sigma-Aldrich), and 5\% nonfat milk powder (Bio-Rad). The following primary antibodies were diluted 1:1000 with the blocking solution and incubated overnight with the blots: rabbit anti-phospho-Y1054/1055 TYK2 (Cell Signaling Technology), rabbit anti-phospho-1022/1023 JAK1 (Cell Signaling Technology), rabbit anti-phospho-1007/1008 JAK2 (Cell Signaling Technology), mouse anti-phospho-Y701 STAT1 (BD), rabbit anti-phospho-Y705 STAT3 (Cell Signaling Technology), rabbit anti-phospho-693 STAT4 (Cell Signaling Technology), mouse anti-STAT1 (BD), mouse anti-STAT3 (Cell Signaling Technology), rabbit anti-STAT4 (Cell Signaling Technology), mouse anti-tubulin (Santa Cruz Biotechnology Inc.), and rabbit anti-GAPDH (glyceraldehyde-3-phosphate dehydrogenase) (Santa Cruz Biotechnology Inc.) antibodies. The blots were washed three times, for $10 \mathrm{~min}$ per wash, with washing buffer consisting of TBS plus $0.01 \%$ Tween 20 . An anti-rabbit horseradish peroxidase (HRP) or anti-mouse HRP antibody (GE Healthcare) was then added at a dilution of 1:10,000 or 1:5000, respectively, and the blots were incubated for 1 hour. Last, the blots were washed with washing buffer, and antibody binding was detected with the SuperSignal West Femto System (Thermo Fisher Scientific). The membranes were analyzed with an Amersham Imager 600 instrument (GE Healthcare Life Sciences).

For fig. S3D, immunoblots were revealed using enhanced chemiluminescence detection reagent (Western Lightning, PerkinElmer) and signals were acquired with Fuji ImageQuant LAS 4000. The intensity of bands was quantified with MultiGauge software. In IFNstimulated samples, for each protein, the intensity of the phosphorylated band was normalized by the corresponding total protein content. The level of phosphorylated band in control cells was set as 100. All the other Western blots were analyzed and quantified using the ImageJ software [National Institutes of Health (NIH)] following the manufacturer's instructions. The phosphorylation of TYK2, JAK2, JAK1, STAT1, STAT3, and STAT4 for each treatment was normalized with the density of total TYK2, JAK2, JAK1, STAT1, STAT3, and STAT4, respectively, and the quantification was expressed in arbitrary units (relative density). Statistical analysis was performed considering technical replicates for the transduced cells with the TYK2 alleles, and technical and biological replicates for EBV-B and HVS-T cell lines derived from controls and patients.

\section{Population genetic analysis}

We investigated the occurrence of strong negative selection acting on the candidate TYK2 missense variants over the last few hundreds of generations, by comparing the current allele frequency of these variants in Europeans with that estimated from the low-coverage sequenced genomes of 22 individuals from Late Stone Age (LSA) Central Europe (52). For a candidate variant at frequency $p_{\mathrm{t}}$ in the current generation and $p_{0}$ during the LSA, we retrieved all variants with a frequency of $p_{0} \pm 1 \%$ during this time period and considered the candidate variant to have been under strong and recent negative selection if its frequency $p_{\mathrm{t}}$ was among the lowest $5 \%$ of values for all the variants retrieved. Only variants that were still segregating in the current European population (CEU, TSI, or FIN from the 1000 Genomes Project) were considered in this analysis.

We checked that these empirical observations were not biased due to sampling or sequencing errors, by performing 100,000 forward simulations under the Wright-Fisher neutral model ( $\mathrm{R}$ code available upon request). We simulated the fate of a neutral allele at frequency $p_{0} 160$ generations ago, in a population of size $N_{\mathrm{e}}=4000$, and retrieved the distribution of its current frequency $p_{\mathrm{t}}(160$ generations later) across all simulations. The lower quantiles of the simulated and observed distributions were largely similar (Fig. 1E), suggesting that our analyses were unbiased.

\section{WES and RNA-seq analyses}

WES was performed as previously described (47). For RNA-seq, reads were mapped with STAR v2.5.3a (90). A genome index specific to our data was first created, and single-end reads were then aligned, in a two-pass mode in which novel splicing junctions are first detected, before final mapping. Read counts were obtained for each gene with HTSeq v0.9.1 (91). Homozygosity rates from exome data were estimated as described previously (47). Gene expression levels were estimated with TPM (transcripts per kilobase million). TPM takes into account the size of each sample library and gene lengths to assess expression levels (92).

Statistical analysis was performed with R v3.2.3 (93) (www. R-project.org/). Gene expression profiles are expressed as the fold change in expression between the values obtained before and after stimulation. These profiles were compared between the different groups of individuals: controls $(n=2)$, TYK2 P1104A $(n=2)$,

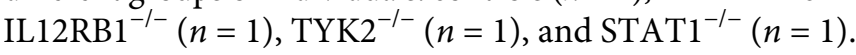

\section{Variant enrichment analysis}

We performed an enrichment analysis of TYK2 variants in our two cohorts of 463 MSMD patients and 454 tuberculosis patients. We used as controls 2835 individuals of diverse ethnic origin (as shown in PCA of fig. S1C) from our in-house database who were patients with various genetically unexplained non-mycobacterial infections, as well as the 2504 individuals of the 1000 Genomes Project, leading to a total of 5339 controls. The proportion of individuals with specific TYK2 variants in each cohort were compared by means of logistic regression using the likelihood ratio test. To account for the ethnic heterogeneity of the cohorts, the first three principal components of the PCA were systematically included in the logistic regression model, as previously described (48). ORs were also estimated by logistic regression and adjusted for ethnic heterogeneity. 


\section{SUPPLEMENTARY MATERIALS}

immunology.sciencemag.org/cgi/content/full/3/30/eaau8714/DC1 Materials and Methods

Case Reports

Fig. S1. Population and medical genetics.

Fig. S2. Response to IFN- $\alpha / \beta$, IL-10, IL-12, and IL-23 in TYK2-deficient cell lines transduced with different $T Y K 2$ alleles.

Fig. S3. Response to IFN- $\alpha / \beta$ in cell lines with different TYK2 genotypes.

Fig. S4. Response to IL-12 and IL-10 in cell lines with different TYK2 genotypes.

Fig. S5. Response to IL-23 in cell lines with different TYK2 genotypes.

Fig. S6. Induction of target genes after IL-10, IFN- $\alpha$, and IL-23 stimulation in cell lines with different TYK2 genotypes.

Fig. S7. Auto- and transphosphorylation of P1104A TYK2 and P1057A JAK2.

Fig. S8. Analysis of leukocytes with different TYK2 genotypes.

Table S1. Summary of the TYK2 genotypes among the different cohorts of patients and healthy individuals.

Table S2. Raw data used to generate dot plots and bar graphs.

References (94-96)

\section{REFERENCES AND NOTES}

1. R. M. G. J. Houben, P. J. Dodd, The global burden of latent tuberculosis infection: A re-estimation using mathematical modelling. PLOS Med. 13, e1002152 (2016).

2. M. W. Borgdorff, M. Sebek, R. B. Geskus, K. Kremer, N. Kalisvaart, D. van Soolingen, The incubation period distribution of tuberculosis estimated with a molecular epidemiological approach. Int. J. Epidemiol. 40, 964-970 (2011).

3. H. Esmail, C. E. Barry 3rd, D. B. Young, R. J. Wilkinson, The ongoing challenge of latent tuberculosis. Philos. Trans. R. Soc. Lond. Ser. B Biol. Sci. 369, 20130437 (2014).

4. World Health Organization, Global Tuberculosis Report (World Health Organization, 2015).

5. L. Abel, J. El-Baghdadi, A. A. Bousfiha, J.-L. Casanova, E. Schurr, Human genetics of tuberculosis: A long and winding road. Philos. Trans. R. Soc. Lond. Ser. B Biol. Sci. 369, 20130428 (2014).

6. B. J. Marais, R. P. Gie, H. S. Schaaf, N. Beyers, P. R. Donald, J. R. Starke, Childhood pulmonary tuberculosis: Old wisdom and new challenges. Am. J. Respir. Crit. Care Med. 173, 1078-1090 (2006)

7. J. L. Casanova, L. Abel, Genetic dissection of immunity to mycobacteria: The human model. Annu. Rev. Immunol. 20, 581-620 (2002).

8. A. Alcaïs, C. Fieschi, L. Abel, J.-L. Casanova, Tuberculosis in children and adults: Two distinct genetic diseases. J. Exp. Med. 202, 1617-1621 (2005).

9. L. Abel, J. Fellay, D. W. Haas, E. Schurr, G. Srikrishna, M. Urbanowski, N. Chaturvedi, S. Srinivasan, D. H. Johnson, W. R. Bishai, Genetics of human susceptibility to active and latent tuberculosis: Present knowledge and future perspectives. Lancet Infect. Dis. 18, e64-e75 (2018).

10. A. Y. Kreins, M. J. Ciancanelli, S. Okada, X.-F. Kong, N. Ramírez-Alejo, S. S. Kilic, J. El Baghdadi, S. Nonoyama, S. A. Mahdaviani, F. Ailal, A. Bousfiha, D. Mansouri, E. Nievas, C. S. Ma, G. Rao, A. Bernasconi, H. Sun Kuehn, J. Niemela, J. Stoddard, P. Deveau, A. Cobat, S. El Azbaoui, A. Sabri, C. K. Lim, M. Sundin, D. T. Avery, R. Halwani, A. V. Grant, B. Boisson, D. Bogunovic, Y. Itan, M. Moncada-Velez, R. Martinez-Barricarte, M. Migaud, C. Deswarte, L. Alsina, D. Kotlarz, C. Klein, I. Muller-Fleckenstein, B. Fleckenstein, V. Cormier-Daire, S. Rose-John, C. Picard, L. Hammarstrom, A. Puel, S. Al-Muhsen, L. Abel, D. Chaussabel, S. D. Rosenzweig, Y. Minegishi, S. G. Tangye, J. Bustamante, J.-L. Casanova, S. Boisson-Dupuis, Human TYK2 deficiency: Mycobacterial and viral infections without hyper-lgE syndrome. J. Exp. Med. 212, 1641-1662 (2015).

11. S. Boisson-Dupuis, J. Bustamante, J. El-Baghdadi, Y. Camcioglu, N. Parvaneh, S. El Azbaoui, A. Agader, A. Hassani, N. El Hafidi, N. A. Mrani, Z. Jouhadi, F. Ailal, J. Najib, I. Reisli, A. Zamani, S. Yosunkaya, S. Gulle-Girit, A. Yildiran, F. E. Cipe, S. H. Torun, A. Metin, B. Y. Atikan, N. Hatipoglu, C. Aydogmus, S. S. Kilic, F. Dogu, N. Karaca, G. Aksu, N. Kutukculer, M. Keser-Emiroglu, A. Somer, G. Tanir, C. Aytekin, P. Adimi, S. A. Mahdaviani, S. Mamishi, A. Bousfiha, O. Sanal, D. Mansouri, J. L. Casanova, L. Abel, Inherited and acquired immunodeficiencies underlying tuberculosis in childhood. Immunol. Rev. 264, 103-120 (2015).

12. J. Bustamante, S. Boisson-Dupuis, L. Abel, J. L. Casanova, Mendelian susceptibility to mycobacterial disease: Genetic, immunological, and clinical features of inborn errors of IFN- $\gamma$ immunity. Semin. Immunol. 26, 454-470 (2014).

13. S. Boisson-Dupuis, J. El Baghdadi, N. Parvaneh, A. Bousfiha, J. Bustamante, J. Feinberg, A. Samarina, A. V. Grant, L. Janniere, N. El Hafidi, A. Hassani, D. Nolan, J. Najib, Y. Camcioglu, N. Hatipoglu, C. Aydogmus, G. Tanir, C. Aytekin, M. Keser, A. Somer, G. Aksu, N. Kutukculer, D. Mansouri, A. Mahdaviani, S. Mamishi, A. Alcais, L. Abel, J. L. Casanova, IL-12Rß1 deficiency in two of fifty children with severe tuberculosis from Iran, Morocco, and Turkey. PLOS ONE 6, e18524 (2011)

14. P. Tabarsi, M. Marjani, N. Mansouri, P. Farnia, S. Boisson-Dupuis, J. Bustamante, L. Abel, P. Adimi, J.-L. Casanova, D. Mansouri, Lethal tuberculosis in a previously healthy adult with IL-12 receptor deficiency. J. Clin. Immunol. 31, 537-539 (2011).
15. F. Altare, A. Ensser, A. Breiman, J. Reichenbach, J. E. Baghdadi, A. Fischer, J.-F. Emile, J.-L. Gaillard, E. Meinl, J.-L. Casanova, Interleukin-12 receptor $\beta 1$ deficiency in a patient with abdominal tuberculosis. J. Infect. Dis. 184, 231-236 (2001).

16. I. Caragol, M. Raspall, C. Fieschi, J. Feinberg, M. N. Larrosa, M. Hernandez, C. Figueras, J.-M. Bertrán, J. L. Casanova, T. Español, Clinical tuberculosis in 2 of 3 siblings with interleukin-12 receptor $\beta 1$ deficiency. Clin. Infect. Dis. 37, 302-306 (2003).

17. N. Özbek, C. Fieschi, B. T. Yilmaz, L. De Beaucoudrey, Y. E. Bikmaz, J. Feinberg, J.-L. Casanova, Interleukin-12 receptor beta 1 chain deficiency in a child with disseminated tuberculosis. Clin. Infect. Dis. 40, e55-e58 (2005).

18. F. Altare, A. Durandy, D. Lammas, J.-F. Emile, S. Lamhamedi, F. Le Deist, P. Drysdale, E. Jouanguy, R. Döffinger, F. Bernaudin, O. Jeppsson, J. A. Gollob, E. Meinl, A. W. Segal, A. Fischer, D. Kumararatne, J.-L. Casanova, Impairment of mycobacterial immunity in human interleukin-12 receptor deficiency. Science 280, 1432-1435 (1998).

19. C. Fieschi, S. Dupuis, E. Catherinot, J. Feinberg, J. Bustamante, A. Breiman, F. Altare, R. Baretto, F. Le Deist, S. Kayal, H. Koch, D. Richter, M. Brezina, G. Aksu, P. Wood, S. Al-Jumaah, M. Raspall, A. J. Da Silva Duarte, D. Tuerlinckx, J. L. Virelizier, A. Fischer, A. Enright, J. Bernhöft, A. M. Cleary, C. Vermylen, C. Rodriguez-Gallego, G. Davies, R. Blütters-Sawatzki, C. A. Siegrist, M. S. Ehlayel, V. Novelli, W. H. Haas, J. Levy, J. Freihorst, S. Al-Hajjar, D. Nadal, D. De Moraes Vasconcelos, O. Jeppsson, N. Kutukculer, K. Frecerova, I. Caragol, D. Lammas, D. S. Kumararatne, L. Abel, J. L. Casanova, Low penetrance, broad resistance, and favorable outcome of interleukin 12 receptor $\beta 1$ deficiency: Medical and immunological implications. J. Exp. Med. 197, 527-535 (2003)

20. L. de Beaucoudrey, A. Samarina, J. Bustamante, A. Cobat, S. Boisson-Dupuis, J. Feinberg, S. Al-Muhsen, L. Jannière, Y. Rose, M. de Suremain, X. F. Kong, O. Filipe-Santos, A. Chapgier, C. Picard, A. Fischer, F. Dogu, A. Ikinciogullari, G. Tanir, S. Al-Hajjar, S. Al-Jumaah, H. H. Frayha, Z. AlSum, S. Al-Ajaji, A. Alangari, A. Al-Ghonaium, P. Adimi, D. Mansouri, I. Ben-Mustapha, J. Yancoski, B. Z. Garty, C. Rodriguez-Gallego, I. Caragol, N. Kutukculer, D. S. Kumararatne, S. Patel, R. Doffinger, A. Exley, O. Jeppsson, J. Reichenbach, D. Nadal, Y. Boyko, B. Pietrucha, S. Anderson, M. Levin, L. Schandené, K. Schepers, A. Efira, F. Mascart, M. Matsuoka, T. Sakai, C. A. Siegrist, K. Frecerova, R. Blüetters-Sawatzki, J. Bernhoft, J. Freihorst, U. Baumann, D. Richter, F. Haerynck, F. De Baets, V. Novelli, D. Lammas, C. Vermylen, D. Tuerlinckx, C. Nieuwhof, M. Pac, W. H. Haas, I. Müller-Fleckenstein, B. Fleckenstein, J. Levy, R. Raj, A. C. Cohen, D. B. Lewis, S. M. Holland, K. D. Yang, X. Wang, L. Jiang, X. Yang, C. Zhu, Y. Xie, P. P. Lee, K. W. Chan, T. X. Chen, G. Castro, I. Natera, A. Codoceo, A. King, L. Bezrodnik, D. Di Giovani, M. I. Gaillard, D. de Moraes-Vasconcelos, A. S. Grumach, A. J. da Silva Duarte, R. Aldana, F. J. Espinosa-Rosales, M. Bejaoui, A. A. Bousfiha, J. E. Baghdadi, N. Ozbek, G. Aksu, M. Keser, A. Somer, N. Hatipoglu, C. Aydogmus, S. Asilsoy, Y. Camcioglu, S. Gulle, T. T. Ozgur, M. Ozen, M. Oleastro, A. Bernasconi, S. Mamishi, N. Parvaneh, S. Rosenzweig, R. Barbouche, S. Pedraza, Y. L. Lau, M. S. Ehlayel, C. Fieschi, L. Abel, O. Sanal, J. L. Casanova, Revisiting human IL-12R $\beta 1$ deficiency: A survey of 141 patients from 30 countries. Medicine 89, 381-402 (2010).

21. C. Fieschi, M. Bosticardo, L. De Beaucoudrey, S. Boisson-Dupuis, J. Feinberg, O. F. Santos, J. Bustamante, J. Levy, F. Candotti, J.-L. Casanova, A novel form of complete IL-12/IL-23 receptor $\beta 1$ deficiency with cell surface-expressed nonfunctional receptors. Blood 104, 2095-2101 (2004)

22. E. van deVosse, M. H. Haverkamp, N. Ramirez-Alejo, M. Martinez-Gallo, L. Blancas-Galicia, A. Metin, B. Z. Garty, C. Sun-Tan, A. Broides, R. A. de Paus, Ö. Keskin, D. Cağdass, I. Tezcan, E. Lopez-Ruzafa, J. I. Arostegui, J. Levy, F. J. Espinosa-Rosales, Ö. Sanal, L. Santos-Argumedo, J. L. Casanova, S. Boisson-Dupuis, J. T. van Dissel, J. Bustamante, IL-12Rß1 deficiency: Mutation update and description of the IL12RB1 variation database. Hum. Mutat. 34, 1329-1339 (2013).

23. J. Rosain, C. Oleaga-Quintas, C. Deswarte, H. Verdin, S. Marot, G. Syridou, M. Mansouri, S. A. Mahdaviani, E. Venegas-Montoya, M. Tsolia, M. Mesdaghi, L. Chernyshova, Y. Stepanovskiy, N. Parvaneh, D. Mansouri, S. Pedraza-Sánchez, A. Bondarenko, S. E. Espinosa-Padilla, M. A. Yamazaki-Nakashimada, A. Nieto-Patlán, G. Kerner, N. Lambert, C. Jacques, E. Corvilain, M. Migaud, V. Grandin, M. T. Herrera, F. Jabot-Hanin S. Boisson-Dupuis, C. Picard, P. Nitschke, A. Puel, F. Tores, L. Abel, L. Blancas Galicia, E. De Baere, C. Bole-Feysot, J. L. Casanova, J. Bustamante, Alu-elements in IL12RB1 locus likely contributing to copy number variations and Mendelian susceptibility to mycobacterial diseases. J. Clin. Immunol. 38, 617-627 (2018).

24. R. de Jong, F. Altare, I. A. Haagen, D. G. Elferink, T. Boer, P. J. C. van Breda Vriesman, P. J. Kabel, J. M. Draaisma, J. T. van Dissel, F. P. Kroon, J.-L. Casanova, T. H. M. Ottenhoff, Severe mycobacterial and Salmonella infections in interleukin-12 receptor-deficient patients. Science 280, 1435-1438 (1998)

25. M. Ouederni, O. Sanal, A. Ikincioğullari, I. Tezcan, F. Dogu, I. Sologuren, S. Pedraza-Sanchez, M. Keser, G. Tanir, C. Nieuwhof, E. Colino, D. Kumararatne, J. Levy, N. Kutukculer, C. Aytekin, E. Herrera-Ramos, M. Bhatti, N. Karaca, R. Barbouche, A. Broides, E. Goudouris, J. L. Franco, N. Parvaneh, I. Reisli, A. Strickler, A. Shcherbina, A. Somer, A. Segal, A. Angel-Moreno, J. L. Lezana-Fernandez, M. Bejaoui, M. B. Valle, S. Kachboura, T. Sentongo, I. Ben-Mustapha, J. Bustamante, C. Picard, A. Puel, S. Boisson-Dupuis, L. Abel, J.-L. Casanova, C. Rodriguez-Gallego, Clinical features of candidiasis in patients with inherited interleukin 12 receptor $\beta 1$ deficiency. Clin. Infect. Dis. 58, 204-213 (2014). 
26. M. J. Newport, C. M. Huxley, S. Huston, C. M. Hawrylowicz, B. A. Oostra, R. Williamson, M. Levin, A mutation in the interferon- $\gamma$-receptor gene and susceptibility to mycobacterial infection. N. Engl. J. Med. 335, 1941-1949 (1996).

27. E. Jouanguy, F. Altare, S. Lamhamedi, P. Revy, J.-F. Emile, M. Newport, M. Levin S. Blanche, E. Seboun, A. Fischer, J.-L. Casanova, Interferon- $\gamma$-receptor deficiency in an infant with fatal bacille Calmette-Guérin infection. N. Engl. J. Med. 335, 1956-1961 (1996).

28. L. de Beaucoudrey, A. Puel, O. Filipe-Santos, A. Cobat, P. Ghandil, M. Chrabieh, J. Feinberg, H. von Bernuth, A. Samarina, L. Janniere, C. Fieschi, J. L. Stephan, C. Boileau, S. Lyonnet, G. Jondeau, V. Cormier-Daire, M. Le Merrer, C. Hoarau, Y. Lebranchu, O. Lortholary, M. O. Chandesris, F. Tron, E. Gambineri, L. Bianchi, C. Rodriguez-Gallego, S. E. Zitnik, J. Vasconcelos, M. Guedes, A. B. Vitor, L. Marodi, H. Chapel, B. Reid, C. Roifman, D. Nadal, J. Reichenbach, I. Caragol, B. Z. Garty, F. Dogu, Y. Camcioglu, S. Gulle, O. Sanal, A. Fischer, L. Abel, B. Stockinger, C. Picard, J. L. Casanova, Mutations in STAT3 and IL12RB1 impair the development of human IL-17-producing T cells. J. Exp. Med. 205, 1543-1550 (2008).

29. A. Puel, S. Cypowyj, J. Bustamante, J. F. Wright, L. Liu, H. K. Lim, M. Migaud, L. Israel, M. Chrabieh, M. Audry, M. Gumbleton, A. Toulon, C. Bodemer, J. El-Baghdadi, M. Whitters, T. Paradis, J. Brooks, M. Collins, N. M. Wolfman, S. Al-Muhsen, M. Galicchio, L. Abel, C. Picard, J.-L. Casanova, Chronic mucocutaneous candidiasis in humans with inborn errors of interleukin-17 immunity. Science 332, 65-68 (2011).

30. Y. Ling, S. Cypowyj, C. Aytekin, M. Galicchio, Y. Camcioglu, S. Nepesov, A. Ikinciogullari, F. Dogu, A. Belkadi, R. Levy, M. Migaud, B. Boisson, A. Bolze, Y. Itan, N. Goudin, J. Cottineau, C. Picard, L. Abel, J. Bustamante, J.-L. Casanova, A. Puel, Inherited IL-17RC deficiency in patients with chronic mucocutaneous candidiasis. J. Exp. Med. 212, 619-631 (2015).

31. B. Boisson, C. Wang, V. Pedergnana, L. Wu, S. Cypowyj, M. Rybojad, A. Belkadi, C. Picard, L. Abel, C. Fieschi, A. Puel, X. Li, J. L. Casanova, An ACT1 mutation selectively abolishes interleukin-17 responses in humans with chronic mucocutaneous candidiasis. Immunity 39, 676-686 (2013).

32. R. Lévy, S. Okada, V. Béziat, K. Moriya, C. Liu, L. Y. A. Chai, M. Migaud, F. Hauck, A. Al Ali, C. Cyrus, C. Vatte, T. Patiroglu, E. Unal, M. Ferneiny, N. Hyakuna, S. Nepesov, M. Oleastro, A. Ikinciogullari, F. Dogu, T. Asano, O. Ohara, L. Yun, E. Della Mina, D. Bronnimann, Y. Itan, F. Gothe, J. Bustamante, S. Boisson-Dupuis, N. Tahuil, C. Aytekin, A. Salhi, S. Al Muhsen, M. Kobayashi, J. Toubiana, L. Abel, X. Li, Y. Camcioglu, F. Celmeli, C. Klein, S. A. AlKhater, J. L. Casanova, A. Puel, Genetic, immunological, and clinical features of patients with bacterial and fungal infections due to inherited IL-17RA deficiency. Proc. Natl. Acad. Sci. U.S.A. 113, E8277-E8285 (2016).

33. S. S. Kilic, M. Hacimustafaoglu, S. Boisson-Dupuis, A. Y. Kreins, A. V. Grant, L. Abel, J.-L. Casanova, A patient with tyrosine kinase 2 deficiency without hyper-lgE syndrome. J. Pediatr. 160, 1055-1057 (2012).

34. Y. Minegishi, M. Saito, T. Morio, K. Watanabe, K. Agematsu, S. Tsuchiya, H. Takada, T. Hara, N. Kawamura, T. Ariga, H. Kaneko, N. Kondo, I. Tsuge, A. Yachie, Y. Sakiyama, T. Iwata, F. Bessho, T. Ohishi, K. Joh, K. Imai, K. Kogawa, M. Shinohara, M. Fujieda, H. Wakiguchi S. Pasic, M. Abinun, H. D. Ochs, E. D. Renner, A. Jansson, B. H. Belohradsky, A. Metin, N. Shimizu, S. Mizutani, T. Miyawaki, S. Nonoyama, H. Karasuyama, Human tyrosine kinase 2 deficiency reveals its requisite roles in multiple cytokine signals involved in innate and acquired immunity. Immunity 25, 745-755 (2006)

35. S. Fuchs, P. Kaiser-Labusch, J. Bank, S. Ammann, A. Kolb-Kokocinski, C. Edelbusch, H. Omran, S. Ehl, Tyrosine kinase 2 is not limiting human antiviral type III interferon responses. Eur. J. Immunol. 46, 2639-2649 (2016).

36. V. Sancho-Shimizu, R. P.de Diego, E. Jouanguy, S.-Y. Zhang, J.-L. Casanova, Inborn errors of anti-viral interferon immunity in humans. Current Opin. Virol. 1, 487-496 (2011).

37. K. R. Engelhardt, B. Grimbacher, IL-10 in humans: Lessons from the gut, IL-10/IL-10 receptor deficiencies, and IL-10 polymorphisms. Curr. Top. Microbiol. Immunol. 380, 1-18 (2014).

38. D. S. Shouval, J. Ouahed, A. Biswas, J. A. Goettel, B. H. Horwitz, C. Klein, A. M. Muise, S. B. Snapper, Interleukin 10 receptor signaling: Master regulator of intestinal mucosal homeostasis in mice and humans. Adv. Immunol. 122, 177-210 (2014).

39. Z. Li, M. Gakovic, J. Ragimbeau, M.-L. Eloranta, L. Rönnblom, F. Michel, S. Pellegrini, Two rare disease-associated Tyk2 variants are catalytically impaired but signaling competent. J. Immunol. 190, 2335-2344 (2013).

40. S. J. Sohn, K. Barrett, A. Van Abbema, C. Chang, P. B. Kohli, H. Kanda, J. Smith, Y. Lai, A. Zhou, B. Zhang, W. Yang, K. Williams, C. Macleod, C. A. Hurley, J. J. Kulagowski, N. Lewin-Koh, H. S. Dengler, A. R. Johnson, N. Ghilardi, M. Zak, J. Liang, W. S. Blair, S. Magnuson, L. C. Wu, A restricted role for TYK2 catalytic activity in human cytokine responses revealed by novel TYK2-selective inhibitors. J. Immunol. 191, 2205-2216 (2013).

41. C. A. Dendrou, A. Cortes, L. Shipman, H. G. Evans, K. E. Attfield, L. Jostins, T. Barber, G. Kaur, S. B. Kuttikkatte, O. A. Leach, C. Desel, S. L. Faergeman, J. Cheeseman, M. J. Neville, S. Sawcer, A. Compston, A. R. Johnson, C. Everett, J. I. Bell, F. Karpe, M. Ultsch, C. Eigenbrot, G. McVean, L. Fugger, Resolving TYK2 locus genotype-to-phenotype differences in autoimmunity. Sci. Transl. Med. 8, 363 ra149 (2016).
42. M. Lek, K. J. Karczewski, E. V. Minikel, K. E. Samocha, E. Banks, T. Fennell, A. H. O’Donnell-Luria, J. S. Ware, A. J. Hill, B. B. Cummings, T. Tukiainen, D. P. Birnbaum, J. A. Kosmicki, L. E. Duncan, K. Estrada, F. Zhao, J. Zou, E. Pierce-Hoffman, J. Berghout, D. N. Cooper, N. Deflaux, M. DePristo, R. Do, J. Flannick, M. Fromer, L. Gauthier, J. Goldstein, N. Gupta, D. Howrigan, A. Kiezun, M. I. Kurki, A. L. Moonshine, P. Natarajan, L. Orozco, G. M. Peloso, R. Poplin, M. A. Rivas, V. Ruano-Rubio, S. A. Rose, D. M. Ruderfer, K. Shakir, P. D. Stenson, C. Stevens, B. P. Thomas, G. Tiao, M. T. Tusie-Luna, B. Weisburd, H.-H. Won, D. Yu, D. M. Altshuler, D. Ardissino, M. Boehnke, J. Danesh, S. Donnelly, R. Elosua, J. C. Florez, S. B. Gabriel, G. Getz, S. J. Glatt, C. M. Hultman, S. Kathiresan, M. Laakso, S. McCarroll M. I. McCarthy, D. McGovern, R. McPherson, B. M. Neale, A. Palotie, S. M. Purcell, D. Saleheen, J. M. Scharf, P. Sklar, P. F. Sullivan, J. Tuomilehto, M. T. Tsuang, H. C. Watkins, J. G. Wilson, M. J. Daly, D. G. MacArthur, Exome Aggregation Consortium, Analysis of protein-coding genetic variation in 60,706 humans. Nature 536, 285-291 (2016).

43. Y. Itan, L. Shang, B. Boisson, M. J. Ciancanelli, J. G. Markle, R. Martinez-Barricarte, E. Scott I. Shah, P. D. Stenson, J. Gleeson, D. N. Cooper, L. Quintana-Murci, S.-Y. Zhang, L. Abel, J.-L. Casanova, The mutation significance cutoff: Gene-level thresholds for variant predictions. Nat. Methods 13, 109-110 (2016).

44. M. Kircher, D. M. Witten, P. Jain, B. J. O'Roak, G. M. Cooper, J. Shendure, A general framework for estimating the relative pathogenicity of human genetic variants. Nat. Genet. 46, 310-315 (2014).

45. 1000 Genomes Project Consortium, A. Auton, L. D. Brooks, R. M. Durbin, E. P. Garrison, H. M. Kang, J. O. Korbel, J. L. Marchini, S. McCarthy, G. A. McVean, G. R. Abecasis, A global reference for human genetic variation. Nature 526, 68-74 (2015).

46. X.-F. Kong, R. Martinez-Barricarte, J. Kennedy, F. Mele, T. Lazarov, E. K. Deenick, C. S. Ma, G. Breton, K. B. Lucero, D. Langlais, A. Bousfiha, C. Aytekin, J. Markle, C. Trouillet, F. Jabot-Hanin, C. S. L. Arlehamn, G. Rao, C. Picard, T. Lasseau, D. Latorre, S. Hambleton, C. Deswarte, Y. Itan, K. Abarca, D. Moraes-Vasconcelos, F. Ailal, A. Ikinciogullari, F. Dogu, I. Benhsaien, A. Sette, L. Abel, S. Boisson-Dupuis, B. Schröder, M. C. Nussenzweig, K. Liu, F. Geissmann, S. G. Tangye, P. Gros, F. Sallusto, J. Bustamante, J.-L. Casanova, Disruption of an antimycobacterial circuit between dendritic and helper T cells in human SPPL2a deficiency. Nat. Immunol. 19, 973-985 (2018).

47. A. Belkadi, V. Pedergnana, A. Cobat, Y. Itan, Q. B. Vincent, A. Abhyankar, L. Shang, J. El Baghdadi, A. Bousfiha; Exome/Array Consortium, A. Alcais, B. Boisson, J.-L. Casanova, L. Abel, Whole-exome sequencing to analyze population structure, parental inbreeding and familial linkage. Proc. Natl. Acad. Sci. U.S.A. 113, 6713-6718 (2016).

48. S. Belkaya, A. R. Kontorovich, M. Byun, S. Mulero-Navarro, F. Bajolle, A. Cobat, R. Josowitz, Y. Itan, R. Quint, L. Lorenzo, S. Boucherit, C. Stoven, S. Di Filippo, L. Abel, S. Y. Zhang, D. Bonnet, B. D. Gelb, J. L. Casanova, Autosomal recessive cardiomyopathy presenting as acute myocarditis. J. Am. Coll. Cardiol. 69, 1653-1665 (2017).

49. J.-L. Casanova, Severe infectious diseases of childhood as monogenic inborn errors of immunity. Proc. Natl. Acad. Sci. U.S.A. 112, E7128-E7137 (2015).

50. J.-L. Casanova, Human genetic basis of interindividual variability in the course of infection. Proc. Natl. Acad. Sci. U.S.A. 112, E7118-E7127 (2015)

51. A. Posa, F. Maixner, B. G. Mende, K. Kohler, A. Osztas, C. Sola, O. Dutour, M. Masson, E. Molnar, G. Palfi, A. Zink, Tuberculosis in late neolithic-early copper age human skeletal remains from Hungary. Tuberculosis 95 (Suppl. 1), S18-S22 (2015).

52. I. Mathieson, I. Lazaridis, N. Rohland, S. Mallick, N. Patterson, S. A. Roodenberg, E. Harney, K. Stewardson, D. Fernandes, M. Novak, K. Sirak, C. Gamba, E. R. Jones, B. Llamas, S. Dryomov, J. Pickrell, J. L. Arsuaga, J. M. de Castro, E. Carbonell, F. Gerritsen, A. Khokhlov, P. Kuznetsov, M. Lozano, H. Meller, O. Mochalov, V. Moiseyev, M. A. Guerra, J. Roodenberg, J. M. Vergès, J. Krause, A. Cooper, K. W. Alt, D. Brown, D. Anthony, C. Lalueza-Fox, W. Haak, R. Pinhasi, D. Reich, Genome-wide patterns of selection in 230 ancient Eurasians. Nature 528, 499-503 (2015).

53. D. Rigante, B. Frediani, L. Cantarini, A comprehensive overview of the hereditary periodic fever syndromes. Clin. Rev. Allergy Immunol. 54, 446-453 (2016).

54. L. W. Powell, R. C. Seckington, Y. Deugnier, Haemochromatosis. Lancet 388, 706-716 (2016).

55. J. Cairns, Matters of Life and Death (Princeton Univ. Press, 1997), pp. 257.

56. R. J. Dubos, J. Dubos, The White Plague: Tuberculosis, Man, and Society (Little Brown, ed. 1, 1952), pp. viii, 277.

57. E. K. Karlsson, D. P. Kwiatkowski, P. C. Sabeti, Natural selection and infectious disease in human populations. Nat. Rev. Genet. 15, 379-393 (2014).

58. I. Cvijović, B. H. Good, E. R. Jerison, M. M. Desai, Fate of a mutation in a fluctuating environment. Proc. Natl. Acad. Sci. U.S.A. 112, E5021-E5028 (2015).

59. S. K. Cohn Jr., Epidemiology of the Black Death and successive waves of plague. Med. Hist. Suppl. 74-100 (2008).

60. R. Martinez-Barricarte, S. J. de Jong, J. Markle, R. de Paus, S. Boisson-Dupuis, J. Bustamante, E. van de Vosse, B. Fleckenstein, J. L. Casanova, Transduction of herpesvirus saimiri-transformed T cells with exogenous genes of interest. Curr. Protoc. Immunol. 115, 7.21C.1-7.21C.12 (2016)

61. R. McKendry, J. John, D. Flavell, M. Müller, I. M. Kerr, G. R. Stark, High-frequency mutagenesis of human cells and characterization of a mutant unresponsive to both alpha and gamma interferons. Proc. Natl. Acad. Sci. U.S.A. 88, 11455-11459 (1991). 
62. S. Pellegrini, J. John, M. Shearer, I. M. Kerr, G. R. Stark, Use of a selectable marker regulated by alpha interferon to obtain mutations in the signaling pathway. Mol. Cell. Biol. 9, 4605-4612 (1989).

63. J. John, R. McKendry, S. Pellegrini, D. Flavell, I. M. Kerr, G. R. Stark, Isolation and characterization of a new mutant human cell line unresponsive to alpha and beta interferons. Mol. Cell. Biol. 11, 4189-4195 (1991).

64. M. H. Shaw, V. Boyartchuk, S. Wong, M. Karaghiosoff, J. Ragimbeau, S. Pellegrini, M. Muller, W. F. Dietrich, G. S. Yap, A natural mutation in the Tyk2 pseudokinase domain underlies altered susceptibility of B10.Q/J mice to infection and autoimmunity. Proc. Natl. Acad. Sci. U.S.A. 100, 11594-11599 (2003).

65. J. Ragimbeau, E. Dondi, A. Alcover, P. Eid, G. Uzé, S. Pellegrini, The tyrosine kinase Tyk2 controls IFNAR1 cell surface expression. EMBO J. 22, 537-547 (2003).

66. M. W. L. Teng, E. P. Bowman, J. J. McElwee, M. J. Smyth, J.-L. Casanova, A. M. Cooper, D. J. Cua, IL-12 and IL-23 cytokines: From discovery to targeted therapies for immunemediated inflammatory diseases. Nat. Med. 21, 719-729 (2015).

67. D. M. Floss, T. Klocker, J. Schroder, L. Lamertz, S. Mrotzek, B. Strobl, H. Hermanns, J. Scheller, Defining the functional binding sites of interleukin 12 receptor $\beta 1$ and interleukin 23 receptor to Janus kinases. Mol. Biol. Cell 27, 2301-2316 (2016).

68. V. Tsui, P. Gibbons, M. Ultsch, K. Mortara, C. Chang, W. Blair, R. Pulk, M. Stanley, M. Starovasnik, D. Williams, M. Lamers, P. Leonard, S. Magnuson, J. Liang, C. Eigenbrot, A new regulatory switch in a JAK protein kinase. Proteins 79, 393-401 (2011).

69. D. Sivanesan, C. Beauchamp, C. Quinou, J. Lee, S. Lesage, S. Chemtob, J. D. Rioux S. W. Michnick, IL23R (interleukin 23 receptor) variants protective against inflammatory bowel diseases (IBD) display loss of function due to impaired protein stability and intracellular trafficking. J. Biol. Chem. 291, 8673-8685 (2016).

70. E. Stefan, S. Aquin, N. Berger, C. R. Landry, B. Nyfeler, M. Bouvier, S. W. Michnick, Quantification of dynamic protein complexes using Renilla luciferase fragment complementation applied to protein kinase A activities in vivo. Proc. Natl. Acad. Sci. U.S.A. 104, 16916-16921 (2007).

71. J. Briscoe, N. C. Rogers, B. A. Witthuhn, D. Watling, A. G. Harpur, A. F. Wilks, G. R. Stark, J. N. Ihle, I. M. Kerr, Kinase-negative mutants of JAK1 can sustain interferon-gammainducible gene expression but not an antiviral state. EMBO J. 15, 799-809 (1996).

72. C. MacLennan, C. Fieschi, D. A. Lammas, C. Picard, S. E. Dorman, O. Sanal, J. M. MacLennan, S. M. Holland, T. H. M. Ottenhoff, J.-L. Casanova, D. S. Kumararatne, Interleukin (IL)-12 and IL-23 are key cytokines for immunity against Salmonella in humans. J. Infect. Dis. 190, 1755-1757 (2004).

73. B. Oppmann, R. Lesley, B. Blom, J. C. Timans, Y. Xu, B. Hunte, F. Vega, N. Yu, J. Wang, K. Singh, F. Zonin, E. Vaisberg, T. Churakova, M.-r. Liu, D. Gorman, J. Wagner, S. Zurawski, Y. Liu, J. S. Abrams, K. W. Moore, D. Rennick, R. de Waal-Malefyt, C. Hannum, J. F. Bazan, R. A. Kastelein, Novel p19 protein engages IL-12p40 to form a cytokine, IL-23, with biological activities similar as well as distinct from IL-12. Immunity 13, 715-725 (2000)

74. K. I. Happel, E. A. Lockhart, C. M. Mason, E. Porretta, E. Keoshkerian, A. R. Odden, S. Nelson, A. J. Ramsay, Pulmonary interleukin-23 gene delivery increases local T-cell immunity and controls growth of Mycobacterium tuberculosis in the lungs. Infect. Immun. 73, 5782-5788 (2005)

75. L. Moens, H. Schaballie, B. Bosch, A. Voet, X. Bossuyt, J.-L. Casanova, S. Boisson-Dupuis, S. G. Tangye, I. Meyts, AD hyper-IgE syndrome due to a novel loss-of-function mutation in STAT3: A diagnostic pursuit won by clinical acuity. J. Clin. Immunol. 37, 12-17 (2017).

76. R. Martínez-Barricarte, J. G. Markle, C. S. Ma, E. K. Deenick, N. Ramírez-Alejo, F. Mele, D. Latorre, S. A. Mahdaviani, C. Aytekin, D. Mansouri, V. Bryant, F. Jabot-Hanin, C. Deswarte, A. Nieto-Patlán, L. Surace, G. Kerner, Y. Itan, S. Jovic, D. T. Avery, N. Wong G. Rao, E. Patin, S. Okada, B. Bigio, B. Boisson, F. Rapaport, Y. Seeleuthner, M. Schmidt, A. Ikinciogullari, F. Dogu, G. Tanir, P. Tabarsi, M. R. Bloursaz, J. K. Joseph, A. Heer, X.-F. Kong, M. Migaud, T. Lazarov, F. Geissmann, B. Fleckenstein, C. L. Arlehamn, A. Sette, A. Puel, J.-F. Emile, E. van de Vosse, L. Quintana-Murci, J. P. Di Santo, L. Abel, S. Boisson-Dupuis, J. Bustamante, S. G. Tangye, F. Sallusto, J.-L. Casanova, Human IFN- $\gamma$ immunity to mycobacteria is governed by both IL-12 and IL-23. Sci. Immunol. 3, eaau6759 (2018).

77. T. Korn, E. Bettelli, M. Oukka, V. K. Kuchroo, IL-17 and Th17 cells. Annu. Rev. Immunol. 27 485-517 (2009)

78. F. Sallusto, Heterogeneity of human $\mathrm{CD}^{+} \mathrm{T}$ cells against microbes. Annu. Rev. Immunol. 34, 317-334 (2016).

79. S. Okada, J. G. Markle, E. K. Deenick, F. Mele, D. Averbuch, M. Lagos, M. Alzahrani, S. Al-Muhsen, R. Halwani, C. S. Ma, N. Wong, C. Soudais, L. A. Henderson, H. Marzouqa, J. Shamma, M. Gonzalez, R. Martinez-Barricarte, C. Okada, D. T. Avery, D. Latorre, C. Deswarte, F. Jabot-Hanin, E. Torrado, J. Fountain, A. Belkadi, Y. Itan, B. Boisson M. Migaud, C. S. L. Arlehamn, A. Sette, S. Breton, J. McCluskey, J. Rossjohn, J.-P. de Villartay, D. Moshous, S. Hambleton, S. Latour, P. D. Arkwright, C. Picard, O. Lantz, D. Engelhard, M. Kobayashi, L. Abel, A. M. Cooper, L. D. Notarangelo, S. Boisson-Dupuis, A. Puel, F. Sallusto, J. Bustamante, S. G. Tangye, J.-L. Casanova, Impairment of immunity to Candida and Mycobacterium in humans with bi-allelic RORC mutations. Science 349, 606-613 (2015)
80. J. L. Casanova, E. Jouanguy, S. Lamhamedi, S. Blanche, A. Fischer, Immunological conditions of children with BCG disseminated infection. Lancet 346, 581 (1995).

81. A. O'Garra, P. S. Redford, F. W. McNab, C. I. Bloom, R. J. Wilkinson, M. P. R. Berry, The immune response in tuberculosis. Annu. Rev. Immunol. 31, 475-527 (2013).

82. N. Fodil, D. Langlais, P. Gros, Primary immunodeficiencies and inflammatory disease: A growing genetic intersection. Trends Immunol. 37, 126-140 (2016).

83. J. F. Brinkworth, L. B. Barreiro, The contribution of natural selection to present-day susceptibility to chronic inflammatory and autoimmune disease. Curr. Opin. Immunol. 31, 66-78 (2014).

84. L. B. Barreiro, L. Quintana-Murci, From evolutionary genetics to human immunology: How selection shapes host defence genes. Nat. Rev. Genet. 11, 17-30 (2010).

85. M. Gadina, C. Johnson, D. Schwartz, M. Bonelli, S. Hasni, Y. Kanno, P. Changelian, A. Laurence, J. J. O'Shea, Translational and clinical advances in JAK-STAT biology: The present and future of jakinibs. J. Leukoc. Biol. 104, 499-514 (2018).

86. K. Papp, K. Gordon, D. Thaci, A. Morita, M. Gooderham, P. Foley, I. G. Girgis, S. Kundu, S. Banerjee, Phase 2 trial of selective tyrosine kinase 2 inhibition in Psoriasis. N. Engl. J. Med. 379, 1313-1321 (2018).

87. D. M. Schwartz, Y. Kanno, A. Villarino, M. Ward, M. Gadina, J. J. O'Shea, JAK inhibition as a therapeutic strategy for immune and inflammatory diseases. Nat. Rev. Drug Discov. 16, 843-862 (2017).

88. S. M. Holland, Immunotherapy of mycobacterial infections. Semin. Respir. Infect. 16, 47-59 (2001).

89. J. Feinberg, C. Fieschi, R. Doffinger, M. Feinberg, T. Leclerc, S. Boisson-Dupuis, C. Picard, J. Bustamante, A. Chapgier, O. Filipe-Santos, C.-L. Ku, L. de Beaucoudrey, J. Reichenbach G. Antoni, R. Baldé, A. Alcaïs, J.-L. Casanova, Bacillus Calmette Guérin triggers the IL-12/ IFN- $\gamma$ axis by an IRAK-4- and NEMO-dependent, non-cognate interaction between monocytes, NK, and T lymphocytes. Eur. J. Immunol. 34, 3276-3284 (2004).

90. A. Dobin, C. A. Davis, F. Schlesinger, J. Drenkow, C. Zaleski, S. Jha, P. Batut, M. Chaisson T. R. Gingeras, STAR: Ultrafast universal RNA-seq aligner. Bioinformatics 29, 15-21 (2013).

91. S. Anders, P. T. Pyl, W. Huber, HTSeq-A Python framework to work with highthroughput sequencing data. Bioinformatics 31, 166-169 (2015)

92. A. Conesa, P. Madrigal, S. Tarazona, D. Gomez-Cabrero, A. Cervera, A. McPherson, M. W. Szcześniak, D. J. Gaffney, L. L. Elo, X. Zhang, A. Mortazavi, A survey of best practices for RNA-seq data analysis. Genome Biol. 17, 13 (2016).

93. R. C. Team, R: A language and environment for statistical computing. R Foundation for Statistical Computing, Vienna, Austria (2015).

94. J. Ragimbeau, E. Dondi, A. Vasserot, P. Romero, G. Uzé, S. Pellegrini, The receptor interaction region of Tyk2 contains a motif required for its nuclear localization. J. Biol. Chem. 276, 30812-30818 (2001).

95. S. N. Vogel, R. M. Friedman, M. M. Hogan, Measurement of antiviral activity induced by interferons $\alpha, \beta$, and $\gamma$. Curr. Protoc. Immunol. Chapter 6, Unit 6.9 (2001).

96. S. Purcell, B. Neale, K. Todd-Brown, L. Thomas, M. A. R. Ferreira, D. Bender, J. Maller, P. Sklar, P. I. W. de Bakker, M. J. Daly, P. C. Sham, PLINK: A tool set for whole-genome association and population-based linkage analyses. Am. J. Hum. Genet. 81, 559-575 (2007)

Acknowledgments: We would like to thank the patients, their relatives, and their physicians. We also thank Y. Nemirovskaya, T. Kochetkov, D. Papandrea, S. O. Lugo Reyes, L. Blancas Galicia, M. Orlova, E. Schurr, A. Bousfiha, L. Lorenzo-Diaz, C. Desvallees, C. Patissier, C. Carvajal, N. Scioscia, F. Zegna-Ratá, and C. Tiznado. Funding: The Laboratory of Human Genetics of Infectious Diseases was supported, in part, by grants from the French National Agency for Research (ANR) under the "Investissement d'avenir" program (grant no. ANR-10-IAHU-01), the TBPATHGEN project (grant no. ANR-14-CE14-0007-01), the GENMSMD project (grant no. ANR-16-CE17-0005-01), the Integrative Biology of Emerging Infectious Diseases Laboratory of Excellence (grant no. ANR-10-LABX-62-IBEID), the European Research Council (ERC; grant no. ERC-2010-AdG-268777), the SCOR Corporate Foundation for Science, the St. Giles Foundation, the National Center for Research Resources and the National Center for Advancing Sciences (NCATS), NIH (grant no. UL1TR001866), the National Institute of Allergy and Infectious Diseases (NIAID) (grant nos. 5R01Al089970, 5R37AI095983, 5U01Al088685, and 5U19Al111143), and The Rockefeller University. Work at the Cytokine Signaling Unit was supported, in part, by a grant from Fondation de la Recherche Médicale to S. Pellegrini (grant no. DEQ20170336741). J.B. was supported by Support of Clinical Research (grant no. SRC2017). C.S.M. and S.G.T. were supported by fellowships and grants from the National Health and Medical Research Council of Australia and the Office of Health and Medical Research of the Government of New South Wales (Australia). M.E.B. was supported by Fondo Nacional de Desarrollo Científico y Tecnológico (FONDECYT; grant no. 1171570) A.C.-N. was supported by Fundação de Amparo a Pesquisa do Estado e de São Paulo (Fapesp) and Conselho Nacional de Desenvolvimento Cientifico e Tecnologico (CNPq). N.R.-A. was supported by fellowships from Consejo Nacional de Ciencia y Tecnología (CONACYT; grant no. 264011) and the Stony Wold-Herbert Fund. Z.L. was supported by the CNRS. J. Markle was supported by the Charles H. Revson Senior Fellowship in Biomedical Sciences and NIAID grant K99AI27932. C.C.J. was the Damon 
Runyon-Richard Lumsden Foundation Physician Scientist supported by the Damon Runyon Cancer Research Foundation (PST-03-15). H.D.O. was supported by the Jeffrey Modell Foundation. N.H. was supported by a Medical Scientist Training Program grant from the National Institute of General Medical Sciences of the NIH under award no. T32GM007739 to the Weill Cornell/Rockefeller/Sloan-Kettering Tri-Institutional MD-PhD Program. The content of this study is the sole responsibility of the authors and does not necessarily represent the official views of the NIH. The Yale Center for Mendelian Genomics (UM1HG006504) is funded by the National Human Genome Research Institute. Funds were also provided by the National Heart, Lung, and Blood Institute. The GSP Coordinating Center (U24 HG008956) contributed to cross-program scientific initiatives and provided logistical and general study coordination. Author contributions: R.N., P.G., C.C.J., S. Pekcan, Z.C., J.I., B.T.C.-C., J.A.T.d.A., H.G.-O., L.O., T.O., A.A., I.A.R., H.S., H.N.A., A.Z., H.A., M.E.B., A.C.-N., A.S., K.A., H.D.O., I.R., E.H.S., J.E.-B., and L.H. took care of the patients, provided clinical samples, and analyzed clinical data. S.B.-D., N.R.-A., E.P., G.K., L.Q.-M., and L.A. performed statistical analysis. S.B.-D., N.R.-A., Z.L., E.P., G.R., G.K., J. Markle, R.M.-B., C.K.L., D.N.K., N.H., C.S.M., Q.Z., K.P., R.F., C.D., J.H., M.B., J. Mulwa, A.G., M.J.C., N.M., C.T., A.P., J.B., S.G.T., S. Pellegrini, L.Q.-M., L.A., and J.-L.C. performed experiments and analyzed the data. D.S., T.L., Y.I., B.B., A. Checchi, F.J.-H., A. Cobat, F.G., S.W.M., I.M.-F., and B.F. provided reagents or computational assistance. S.B.-D., L.A., and J.-L.C. designed and supervised the study and wrote the paper with the assistance of all coauthors. Competing interests: The authors declare that they have no competing interests. Data and materials availability:
The RNA-seq and WES data are available from the Sequence Read Archive (www.ncbi.nlm.nih. gov/sra) (SRA accession no. PRJNA495387).

Submitted 23 July 2018

Accepted 20 November 2018

Published 21 December 2018

10.1126/sciimmunol.aau8714

Citation: S. Boisson-Dupuis, N. Ramirez-Alejo, Z. Li, E. Patin, G. Rao, G. Kerner, C. K. Lim, D. N. Krementsov, N. Hernandez, C. S. Ma, Q. Zhang, J. Markle, R. Martinez-Barricarte, K. Payne, R. Fisch, C. Deswarte, J. Halpern, M. Bouaziz, J. Mulwa, D. Sivanesan, T. Lazarov, R. Naves, P. Garcia, Y. Itan, B. Boisson, A. Checchi, F. Jabot-Hanin, A. Cobat, A. Guennoun, C. C. Jackson, S. Pekcan, Z. Caliskaner, J. Inostroza, B. T. Costa-Carvalho, J. A. Tavares de Albuquerque, H. Garcia-Ortiz, L. Orozco, T. Ozcelik, A. Abid, I. A. Rhorfi, H. Souhi, H. N. Amrani, A. Zegmout, F. Geissmann, S. W. Michnick, I. Muller-Fleckenstein, B. Fleckenstein, A. Puel, M. J. Ciancanelli, N. Marr, H. Abolhassani, M. E. Balcells, A. Condino-Neto, A. Strickler, K. Abarca, C. Teuscher, H. D. Ochs, I. Reisli, E. H. Sayar, J. El-Baghdadi, J. Bustamante, L. Hammarström, S. G. Tangye, S. Pellegrini, L. Quintana-Murci, L. Abel, J.-L. Casanova, Tuberculosis and impaired IL-23dependent IFN- $\gamma$ immunity in humans homozygous for a common TYK2 missense variant. Sci. Immunol. 3, eaau8714 (2018). 